\title{
INL Neutron Interrogation R\&D: FY2010 MPACT End of Year Report
}

D. L. Chichester

E. H Seabury

J. Wharton

S. M. Watson

August 2010

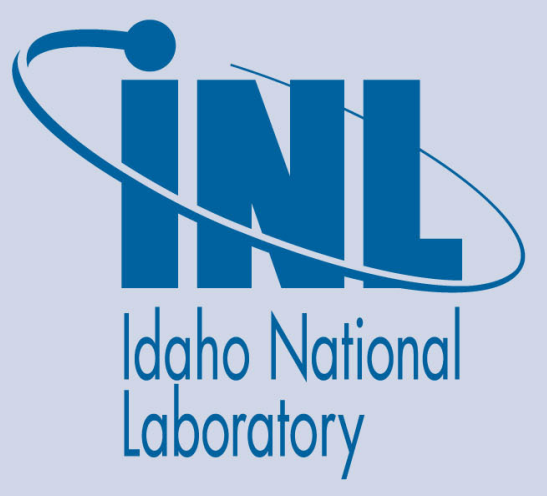

INL is a U.S. Department of Energy National Laboratory operated by Battelle Energy Alliance 


\title{
INL Neutron Interrogation R\&D: FY2010 MPACT End of Year Report
}

\author{
D. L. Chichester, E. H. Seabury, J. Wharton, and S. M. Watson
}

August 2010

\begin{abstract}
Idaho National Laboratory
Idaho Falls, Idaho 83415
\end{abstract}

http://www.inl.gov

\author{
Prepared for the \\ U.S. Department of Energy \\ Office of Nuclear Energy \\ Under DOE Idaho Operations Office \\ Contract DE-AC07-05ID14517
}




\section{DISCLAIMER}

This information was prepared as an account of work sponsored by an agency of the U.S. Government. Neither the U.S. Government nor any agency thereof, nor any of their employees, makes any warranty, expressed or implied, or assumes any legal liability or responsibility for the accuracy, completeness, or usefulness, of any information, apparatus, product, or process disclosed, or represents that its use would not infringe privately owned rights. References herein to any specific commercial product, process, or service by trade name, trade mark, manufacturer, or otherwise, do not necessarily constitute or imply its endorsement, recommendation, or favoring by the U.S. Government or any agency thereof. The views and opinions of authors expressed herein do not necessarily state or reflect those of the U.S. Government or any agency thereof. 


\title{
INL Neutron Interrogation R\&D: FY2010 MPACT End of Year Report
}

\author{
D. L. Chichester, E. H. Seabury, J. Wharton, and S. M. Watson \\ Idaho National Laboratory, Idaho Falls, ID 83415
}

\begin{abstract}
Experiments have been carried out to investigate the feasibility and utility of using neutron interrogation and small-scale, portable prompt gamma-ray neutron activation analysis (PGNAA) instruments for assaying uranium for safeguards applications. Prior work has shown the potential of the PGNAA technique for assaying uranium using reactor-based neutron sources and high-yield electronic neutron generators (ENGs). In this project we adapted Idaho National Laboratory's portable isotopic neutron spectroscopy (PINS) PGNAA system for measuring natural-enrichment uranium yellowcake and metallic depleted uranium and highly enriched uranium. This work used ${ }^{252} \mathrm{Cf}$ as well as deuterium-deuterium (DD) and deuterium-tritium (DT) ENGs. For PGNAA measurements a limiting factor when assaying large objects is the detector dead time due to fastneutron scattering off of the uranium; this limits the maximum useable neutron source strength to $\mathcal{O}\left(10^{7}\right)$ neutrons per second. Under these conditions the low PGNAA reaction cross sections for uranium prohibited the collection of useful uranium PGNAA signatures from either the yellowcake or metallic uranium samples. Measurement of the decay product activation in these materials following irradiation in the PGNAA geometry similarly did not produce useful uranium activation product - fission product signatures. A customized irradiation geometry tailored to optimally thermalize the interrogation neutron source, intended only for generating long-lived activation products - fission products and not intended for PGNAA measurements, might be possible using small scale ENGs but an application need and a modeling and simulation exercise would be recommended before advancing to experiments. Neutron interrogation PGNAA using a DT-ENG was found to be a quick and useful qualitative method for detecting the presence of oxygen in natural-enrichment uranium yellowcake. With a low effort of development work it would be reasonable to expect this measurement could be transitioned to a qualitative technique for assaying oxides as well as other common uranium matrices including nitrides, fluorides, carbides, and sodium-bonded metals. Inert-matrix fuel material confirmation would also be wellserved through this technique. This may be of interest for nuclear Material Protection, Accounting, and Control for Transmutation (MPACT) safeguards applications as a method for confirming material-form declarations in advanced fuel cycle material inventories and for quality control during fuel fabrication.
\end{abstract}

\section{Introduction}

Advanced nuclear fuels are currently under development within the Department of Energy's Fuel Cycle Research and Development program as part of a long-term research effort focused at understanding the behavior of advanced metal and mixed-oxide (MOX) fuels containing minor actinides and long-lived fission products. The aim of this work is to understand how different fuel designs impact the long-term performance of nuclear fuel in order to be able to design and manufacture advanced fuels for use in nextgeneration reactors. As part of the Fuel Cycle Research and Development program's Material Protection, Accounting, and Control for Transmutation (MPACT) program Idaho National Laboratory (INL) has been performing small-scale experiments in a leveraged research program to investigate advanced instrumentation and active 
interrogation measurement techniques to address safeguard measurement challenges associated with advanced fuel cycle activities.[1]

During the 2010 fiscal year INL has worked on a small exploratory research and development project $(\$ 50,000)$ to investigate neutron interrogation and its applications for the MPACT mission. This project started half-way through the 2010 fiscal year; with this late start date it was difficult to plan a full-scale R\&D project due to scheduling and resource conflicts. Recognizing this, modest goals were set for this project to evaluate small-scale, portable neutron interrogation instrumentation used for conducting prompt gamma-ray neutron activation analysis (PGNAA) and to determine what if any role exists for this technology for nondestructive safeguards measurements. Potential application areas might include methods for determining uranium enrichment for non-homogeneous matrices, detecting uranium, and distinguishing uranium from plutonium.

INL has a long history of developing and using portable PGNAA systems for assaying dangerous materials including high explosives, chemical warfare materiel, and other hazardous industrial chemicals and it seemed a logical next-step to explore using these instruments for nuclear material assay measurements. For this project we used already on-hand equipment from INL's PINS (portable isotopic neutron spectroscopy) research group including detectors, test stands, and neutron sources.[2] Surprisingly, after 15 years of research in this area PINS had not been used to measure special nuclear material prior to this project.

\section{Background Information on Neutron Interrogation \& PGNAA of SNM}

Most prior work examining the use of active neutron interrogation to assay special nuclear material (SNM) has involved the measurement of neutrons following exposure to an external neutron source; relying on the fission reaction to generate the observed signatures. A listing of neutron-induced neutron and gamma-ray signatures and pertinent nuclear data is provided in Table 1.[3-6] In practice for many safeguards measurements neutrons are the preferred emission signature due to their specificity of origin (fission) and generally low background interference rate (except for assaying spent fuel) but prior work has also examined using gamma rays. The prompt gamma-rays from fission may in general be viewed as a continuum energy distribution spanning up to 8 to $10 \mathrm{MeV}$ in energy. Measurements of these prompt signals, especially gross gamma-ray measurements at energies above $3 \mathrm{MeV}$, have been used as an indicator for the presence of SNM in active neutron interrogation. At energies below this level the presence of significant gamma-ray background interferences generally precludes the use of gross summing measurements and leads to the need for the use of spectrometry techniques for resolving discrete, individual gamma ray energy lines from background features. Delayed gamma-ray signals from short- and medium-lived fission products may also be used for assay measurements but this requires a very intense neutron source in order to generate a measurable signal.[7,8] 
Table 1 Neutron Induced Fission Signatures.

\begin{tabular}{|c|c|c|c|c|c|c|}
\hline & & Parameter & & ${ }^{235} \mathrm{U}$ & ${ }^{238} \mathrm{U}$ & ${ }^{239} \mathrm{Pu}$ \\
\hline & $\sigma$ & $\begin{array}{l}\text { Fission cross- } \\
\text { section }\end{array}$ & barns & $\begin{array}{c}2734(\text { thermal }) \\
1.287(2 \mathrm{MeV}) \\
2.0839(14.1 \mathrm{MeV})\end{array}$ & $\begin{array}{c}0.534(2 \mathrm{MeV}) \\
1.1516(14.1 \mathrm{MeV})\end{array}$ & $\begin{array}{c}3204(\text { thermal }) \\
1.975(2 \mathrm{MeV}) \\
2.4094(14.1 \mathrm{MeV})\end{array}$ \\
\hline & $\bar{v}_{\mathrm{n}, \text { prompt }}$ & $\begin{array}{c}\text { Average prompt } \\
\text { neutron } \\
\text { yield } \\
\text { (multiplicity) }^{1} \\
\end{array}$ & $\begin{array}{l}\text { prompt } \\
\text { neutrons } \\
\text { per } \\
\text { fission }\end{array}$ & $\begin{array}{c}2.43 \text { (thermal) } \\
2.57 \text { (fission spec.) } \\
4.6(\sim 14 \mathrm{MeV})\end{array}$ & $\begin{array}{l}2.79 \text { (fission spec.) } \\
4.5(\sim 14 \mathrm{MeV})\end{array}$ & $\begin{array}{c}2.87 \text { (thermal) } \\
3.09 \text { (fission spec.) } \\
4.9(\sim 14 \mathrm{MeV})\end{array}$ \\
\hline 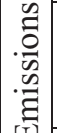 & $\overline{\mathrm{E}}_{\mathrm{n}, \mathrm{prompt}}$ & $\begin{array}{c}\text { Average prompt } \\
\text { neutron } \\
\text { energy }^{2} \\
\end{array}$ & $\mathrm{MeV}$ & $\begin{array}{l}1.935(\text { thermal }) \\
2.03(14 \mathrm{MeV})^{3}\end{array}$ & $1.99(14 \mathrm{MeV})^{3}$ & $\begin{array}{l}2.010(\text { thermal }) \\
2.19(14 \mathrm{MeV})^{3}\end{array}$ \\
\hline 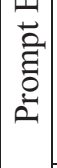 & $\bar{v}_{\gamma, \text { prompt }}$ & $\begin{array}{c}\text { Average prompt } \\
\text { photon } \\
\text { yield }\end{array}$ & $\begin{array}{l}\text { prompt } \\
\text { photons } \\
\text { per } \\
\text { fission }\end{array}$ & $\begin{array}{l}6.60 \pm 0.2 \\
(\text { thermal })^{4}\end{array}$ & $7-8$ & $\begin{array}{l}7.06 \pm 0.2 \\
(\text { thermal })^{4}\end{array}$ \\
\hline & $\overline{\mathrm{E}}_{\gamma, \mathrm{prompt}}$ & $\begin{array}{c}\text { Average prompt } \\
\text { photon } \\
\text { energy }\end{array}$ & $\mathrm{MeV}$ & $\begin{array}{l}0.97 \pm 0.04 \\
(\text { thermal })^{4}\end{array}$ & $\sim 1$ & $\begin{array}{l}0.95 \pm 0.04 \\
{\text { (thermal })^{4}}^{4}\end{array}$ \\
\hline$\tilde{\Xi}$ & $\bar{v}_{\mathrm{n}, \text { delayed }}$ & $\begin{array}{c}\text { Average delayed } \\
\text { neutron } \\
\text { yield }^{1}\end{array}$ & $\begin{array}{l}\text { delayed } \\
\text { neutrons } \\
\text { per } \\
\text { fission }\end{array}$ & $\begin{array}{c}0.0158(\text { thermal }) \\
0.0165(1.45 \mathrm{MeV})\end{array}$ & $0.0412(3.01 \mathrm{MeV})$ & $\begin{array}{c}0.0061(\text { thermal }) \\
0.0063(1.58 \mathrm{MeV})\end{array}$ \\
\hline 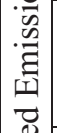 & $\overline{\mathrm{E}}_{\mathrm{n} \text {,delayed }}$ & $\begin{array}{c}\text { Average delayed } \\
\text { neutron } \\
\text { energy }\end{array}$ & $\mathrm{MeV}$ & 0.43 & 0.49 & 0.40 \\
\hline 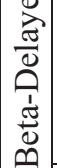 & $\bar{v}_{\gamma, \text { delayed }}$ & $\begin{array}{c}\text { Average delayed } \\
\text { photon } \\
\text { yield }^{6}\end{array}$ & $\begin{array}{l}\text { delayed } \\
\text { photons } \\
\text { per } \\
\text { fission }\end{array}$ & $\begin{array}{l}0.613 \text { short period } \\
3.31 \text { long period }\end{array}$ & $\begin{array}{l}1.42 \text { short period } \\
5.50 \text { long period }\end{array}$ & $\begin{array}{l}0.608 \text { short period } \\
3.26 \text { long period }\end{array}$ \\
\hline & $\overline{\mathrm{E}}_{\gamma \text {,delayed }}$ & $\begin{array}{c}\text { Average delayed } \\
\text { photon } \\
\text { energy }^{7}\end{array}$ & $\mathrm{MeV}$ & 0.96 & 0.92 & 0.98 \\
\hline
\end{tabular}

In contrast with the measurement of continuum gamma-ray signals from prompt fission, PGNAA measures the discrete gamma rays from materials as a result of neutron capture and neutron inelastic scattering. A significant amount of prior work has been performed in this area for assaying fissile material.[7-17] A partial listing of key gamma ray signatures that have been used in the past for PGNAA measurements of SNM is provided in

Table 2. Direct cross-section values have been determined for $(n, \gamma)$ gamma-ray production but are not as well known for many (n,inl) (inelastic neutron scattering)

\footnotetext{
${ }^{1}$ Neutron yields vary depending upon the energy of the neutron that induces fission.

${ }^{2} \mathrm{An}$ increase of $\sim 4 \%$ is expected for these average fission neutron energies in going from thermal-neutroninduced fission to fission-spectrum-induced fission (where the average neutron inducing fission is $\sim 2$ $\mathrm{MeV})$.

${ }^{3}$ From Reference [4].

${ }^{4}$ From Reference [5].

${ }^{5}$ Less than $2 \%$ of prompt fission photons have energies greater than $2 \mathrm{MeV}$.

${ }^{6}$ Delayed photon yields determined for short $(0.2<\mathrm{t}<0.5 \mathrm{sec})$ and long $(0.2<\mathrm{t}<45 \mathrm{sec})$ counting periods.

${ }^{7}$ Delayed photon energies are averaged over a $0.2<\mathrm{t}<45 \mathrm{sec}$ time period. Less than $1.8 \%$ of delayed fission photons are $>2.3 \mathrm{MeV}$ in this time period.
} 
gamma-ray production reactions. The energy dependent cross-sections for neutron capture and inelastic neutron scattering in ${ }^{235} \mathrm{U},{ }^{238} \mathrm{U}$ and ${ }^{16} \mathrm{O}$ are presented in Figure 36 through Figure 38 in the Appendix to this report. Oxygen has been included in this discussion due the ability of PGNAA to discriminate between metallic and oxide uranium samples through direct oxygen assay, as described below. Also shown in the Appendix is the neutron capture cross section for iron, a commonly encountered cause of interference in field PGNAA measurements.

Table 2 Important potential PGNAA reactions for safeguards.[7,11,15,17]

\begin{tabular}{|c|c|c|c|}
\hline $\begin{array}{l}\text { Target } \\
\text { Isotope }\end{array}$ & $\begin{array}{c}\text { Reaction } \\
\text { Mechanisms }\end{array}$ & \multicolumn{2}{|c|}{$\begin{array}{c}\text { PGNAA Gamma Rays } \\
\text { [MEV] }\end{array}$} \\
\hline \multirow{3}{*}{${ }^{235} \mathrm{U}$} & $(\mathrm{n}, \gamma)^{1}$ & $\begin{array}{l}0.244(\sigma=0.023(3) b) \\
0.297(\sigma=0.220(20) b) \\
0.300(\sigma=0.016(3) b) \\
0.909(\sigma=0.026(4) b)\end{array}$ & $\begin{array}{l}0.943(\sigma=0.082(10) b) \\
1.014(\sigma=0.026(4) b)^{2} \\
1.279(\sigma=0.200(10) b) \\
6.395(\sigma=0.0032(4) b)(I=4)\end{array}$ \\
\hline & $(\mathrm{n}, \mathrm{inl})^{3}$ & $\begin{array}{l}0.159(\mathrm{I}=270(80)) \\
0.180(\mathrm{I}=154(40)) \\
0.296(\mathrm{I}=64(9)) \\
0.332(\mathrm{I}=67(9)) \\
0.343(\mathrm{I}=51(7)) \\
0.352(\mathrm{I}=115(9)) \\
0.370(\mathrm{I}=58(7)) \\
0.431(\mathrm{I}=51(4))\end{array}$ & $\begin{array}{l}0.457(\mathrm{I}=51(9)) \\
0.482(\mathrm{I}=93(9)) \\
0.584(\mathrm{I}=63(5)) \\
0.589(\mathrm{I}=94(6)) \\
0.707(\mathrm{I}=100(7)) \\
0.815(\mathrm{I}=59(8)) \\
0.837(\mathrm{I}=76(9))\end{array}$ \\
\hline & $(\text { n.fis })^{4}$ & $\begin{array}{l}0.297\left(\text { from }{ }^{134} \mathrm{Te}\right) \\
0.497\left(\text { from }{ }^{100} \mathrm{Zr}\right)\end{array}$ & $\begin{array}{l}0.706\left(\text { from }^{134} \mathrm{Te}\right) \\
1.279\left(\text { from }{ }^{134} \mathrm{Te}\right)\end{array}$ \\
\hline \multirow[t]{2}{*}{${ }^{238} \mathrm{U}$} & $(\mathrm{n}, \gamma)$ & $\begin{array}{l}0.134(\sigma=0.38(8) b) \\
0.522(\sigma=0.073(3) b) \\
0.539(\sigma=0.099(20) b) \\
0.554(\sigma=0.085(20) b) \\
0.552(\sigma=0.207(5) b) \\
0.594(\sigma=0.108(24) b)\end{array}$ & $\begin{array}{l}0.606(\sigma=0.053(12) b) \\
0.612(\sigma=0.25(5) b) \\
0.630(\sigma=0.073(20) b) \\
0.832(\sigma=0.053(12) b) \\
0.853(\sigma=0.055(12) b) \\
4.060(\sigma=0.186(4) b)(I=70)\end{array}$ \\
\hline & $(\mathrm{n}, \mathrm{inl})$ & $\begin{array}{l}0.159(\mathrm{I}=70(22)) \\
0.584(\mathrm{I}=82(3)) \\
0.650(\mathrm{I}=107(5)) \\
0.687(\mathrm{I}=91(5))\end{array}$ & $\begin{array}{l}0.886(\mathrm{I}=65(4)) \\
1.015(\mathrm{I}=115(7))^{2} \\
1.061(\mathrm{I}=67(4))\end{array}$ \\
\hline${ }^{16} \mathrm{O}$ & $(n$, inl $) \&(n, p)$ & 6.129 & \\
\hline
\end{tabular}

\footnotetext{
${ }^{1}$ This data is taken from reference 17 and is for thermal neutrons from a reactor. For the (n, $\left.\gamma\right)$ reactions with ${ }^{238} \mathrm{U}$ only reactions with a cross section greater than $0.05 \mathrm{~b}$ have been included. The intensity value in the $(\mathrm{n}, \gamma)$ section are from reference 7 and indicate the photons emitted per 1000 thermal-neutron captures; these intensity values have been observed to be significantly less than this for $2 \mathrm{keV}$ neutrons.

${ }^{2}$ Note: These important potential U PGNAA lines are in interference with a PGNAA line from aluminum at $1.014 \mathrm{MeV}$.

${ }^{3}$ For the (n,inl) reactions for ${ }^{235} \mathrm{U}$ and ${ }^{238} \mathrm{U}$ only inelastic gamma rays with a relative intensity $\geq 50$ are listed; absolute intensity data was not identified. This data is taken from reference 11 and is for $3 \mathrm{MeV}$ neutrons.

${ }^{4}$ These short-lived fission product gamma ray suggestions are from reference 15.
} 
The typical PINS ${ }^{252} \mathrm{Cf}$ neutron source is a of $\mathcal{O}(\mu \mathrm{g})$ in mass, producing of $\mathcal{O}\left(10^{7}\right)$ neutrons per second, and typical measurement periods are from 600 to 3600 seconds. At the start of this project it was recognized that these parameters were not ideal for conducting PGNAA measurements with uranium. However, it was also recognized that a study of the feasibility of using PGNAA to identity uranium matrices and to distinguish between oxides and metals had not been done. Further, neither had an assessment been carried out to examine the impact of potential PGNAA-generated interferences for identifying matrix composition. Rather than performing a complex set of measurements a simple set of experiments was determined to be appropriate for assessing the technique and exploring side benefits of using PGNAA on SNM samples for matrix determination.

\section{Experiments}

Testing took place at INL's PINS active neutron interrogation laboratory using a $7.77 \mathrm{~kg}$ sample of natural-enrichment uranium. The estimated uranium elemental mass in this sample was $4.32 \mathrm{~kg}$. This material was contained in five plastic bags within a steel storage drum, as shown in Figure 1. Two neutron sources were used at the PINS lab, a ${ }^{252} \mathrm{Cf}$ source and a deuterium-tritium (DT) electronic neutron generator (ENG) producing approximately $14.1-\mathrm{MeV}$ neutrons. The ${ }^{252} \mathrm{Cf}$ source was $3.3 \mu \mathrm{g}(1.8 \mathrm{mCi})$ of ${ }^{252} \mathrm{Cf}$, producing approximately 8 million neutrons per second. It was placed in a cube of polyethylene, $10-\mathrm{cm}$ long per side either next to or below the yellowcake container. The DT-ENG used for these measurements was a Thermo Electron MP320 and it was operated with a voltage of $70 \mathrm{kV}$ and a beam current of $25 \mu \mathrm{A}$; the neutron yield under these conditions was approximately $3 \times 10^{7}$ neutrons per second. This neutron yield had to be lowered from the ENGs highest possible yield to reduce dead-time aberrations in the gamma-ray detector. The detector used for these measurements was an HPGe detector (relative efficiency at $1.33 \mathrm{MeV}$ of $47.7 \%$ ).
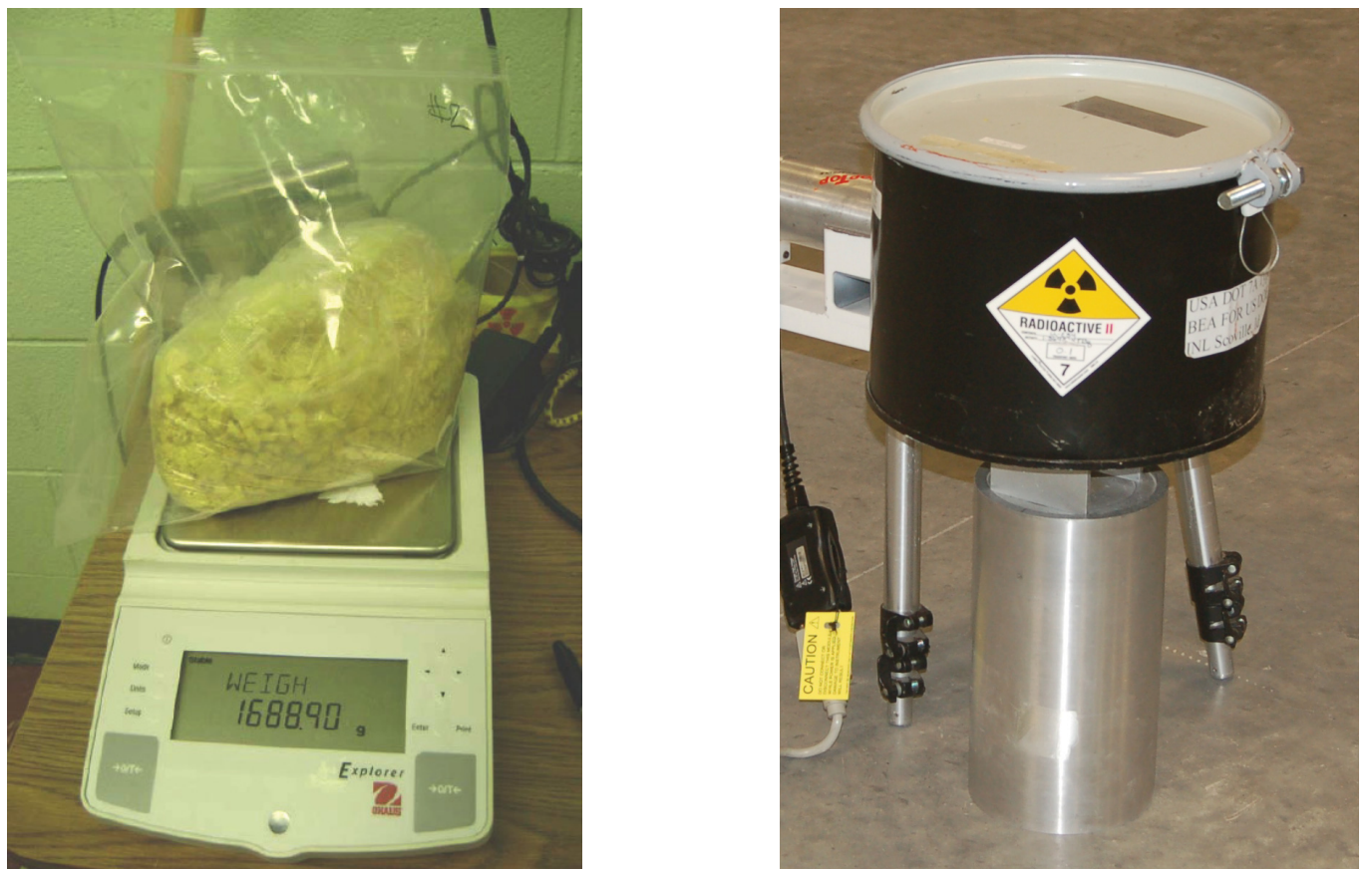

Figure 1 The left panel shows one of five plastic bags filled with unmilled uranium yellowcake; the right panel shows the 5-gallon storage drum which contained all five plastic bags. 
The PINS lab measurements reported here used a polyethylene moderating box to boost the thermal neutron flux incident on the yellowcake. The enclosure consisted of six $5.08-\mathrm{cm}$ thick pieces of polyethylene arranged in a hexagonal pattern to make the walls and a single large $2.5-\mathrm{cm}$ thick cap. Each wall is $61-\mathrm{cm}$ tall and $31.7-\mathrm{cm}$ wide, with additional $6.4-\mathrm{cm}$ diameter hinges on each side joint. The walls were interconnected through the use of 66-cm long polyethylene pins at each of the six connecting joints. The removal of one hinge-pin allowed access to the enclosure for the introduction and change-out of experimental samples. The base of the enclosure was made of aluminum and stands on three $89-\mathrm{cm}$ long aluminum legs. A photo of the irradiation box is shown in Figure 2 for a configuration with the DT-ENG under the sample.
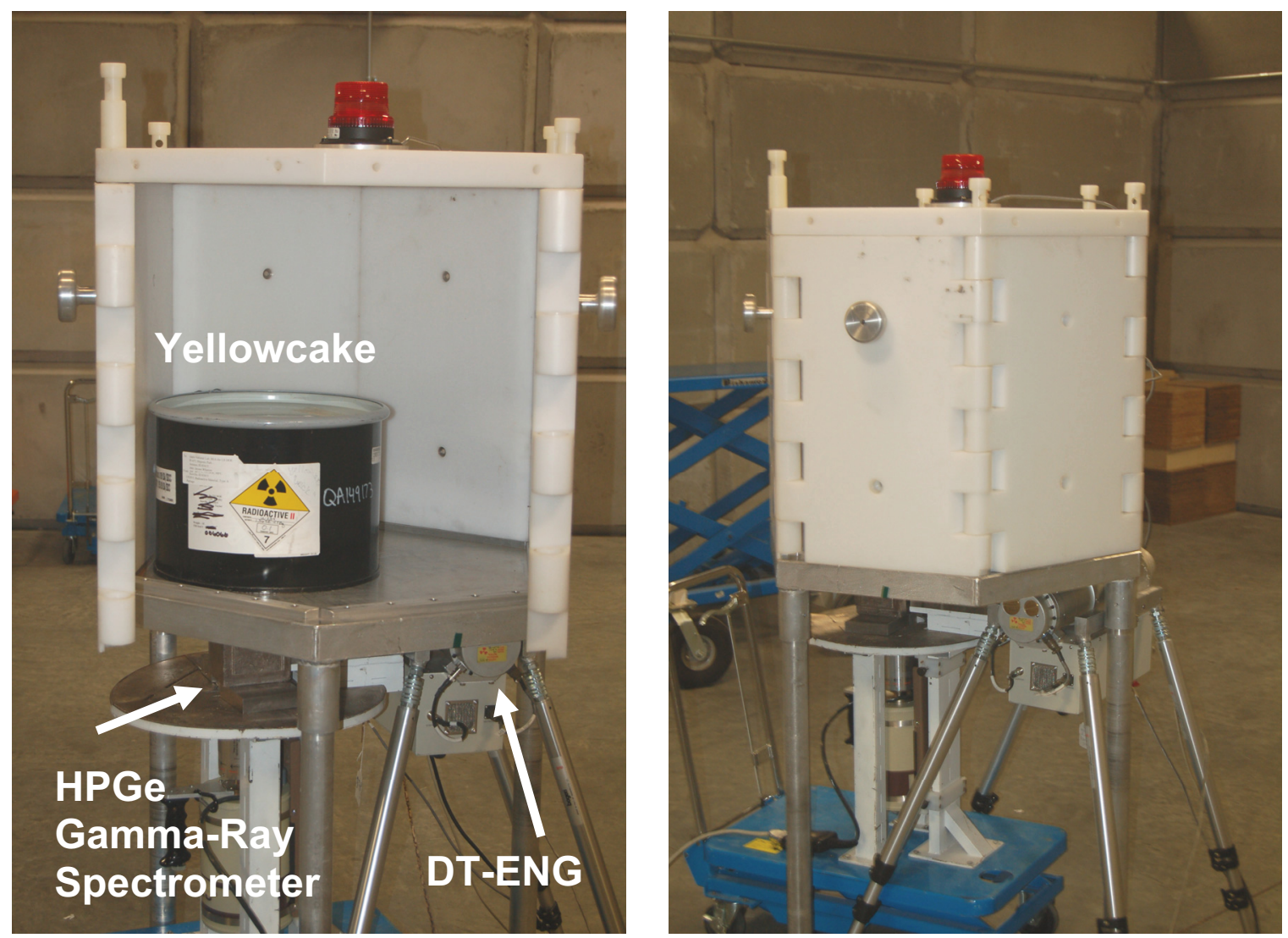

Figure 2 The panel on the left shows the irradiation configuration with the yellowcake in the moderating box. The natural-enrichment yellowcake is in the 5-gallon drum, roughly centered above the HPGe gamma-ray spectrometer but pushed to the side of the polyethylene moderating box. The DT-ENG is also located below the box but it is on the opposite side. Approximately $20 \mathrm{~cm}$ of tungsten was used to shield the detector from the DT-ENG. During experiments the doors to the box were closed, as shown in the right panel.

Testing also took place at INL using metallic depleted uranium (DU) and highly enriched uranium (HEU). The DU was rectangular and measured $11.2 \mathrm{~cm} \mathrm{x} 11.2 \mathrm{~cm} \mathrm{x}$ $2.0 \mathrm{~cm}$, it weighed $4.7 \mathrm{~kg}$. The HEU measured $10.2 \mathrm{~cm} \times 10.2 \mathrm{~cm} \times 0.3 \mathrm{~cm}$ and weighed $0.61 \mathrm{~kg}$. These tests used a deuterium-deuterium (DD) ENG producing approximately 2.5-MeV neutrons. The DD-ENG-to-uranium distance was approximately $20 \mathrm{~cm}$, as was the uranium-to-detector distance. A photo of the set-up using HEU is shown in Figure 3. The DD-ENG yield was approximately $2 \times 10^{6}$ neutrons per second. A fine balance 
must be achieved between maximizing the PGNAA signals while reducing the HPGe dead time due to fast neutrons scattering off of the sample under test; the $20-\mathrm{cm}$ spacing was the closest possible measurement distance for these samples. The same type of detector used with the yellowcake measurements was used for these measurements.

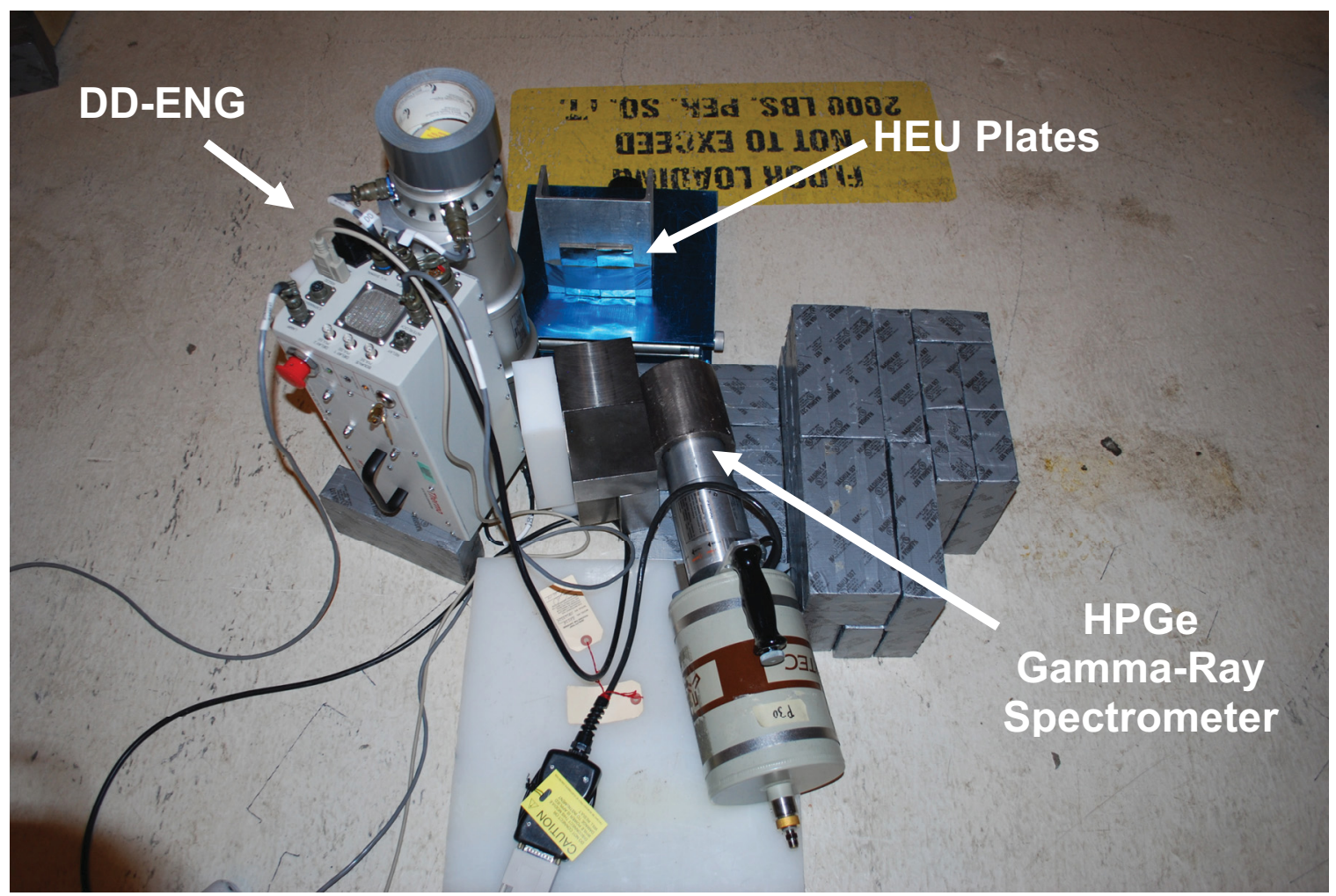

Figure 3 Representative PGNAA test setup for irradiating a sample of HEU with a DD-ENG.

\section{PGNAA - Natural Enrichment Yellowcake}

In Figure 4 data is presented showing the complete $0-11 \mathrm{MeV}$ gamma-ray spectrum from yellow cake irradiated in the polyethylene moderating box using the ${ }^{252} \mathrm{Cf}$ source. Zoomed views of this data are shown in Figure 5 through Figure 15 for successive $0.5-\mathrm{MeV}$ regions of interest. These plots show the passive HPGe spectrum of the yellowcake prior to irradiation, the irradiation box's active-background PGNAA spectrum without the yellowcake sample, and the yellowcake PGNNA spectrum. A small feature is present in Figure 9 at the $4.060-\mathrm{MeV}$ location but from this data it is speculative to draw conclusions from this regarding the ${ }^{238} \mathrm{U}(\mathrm{n}, \gamma)$ response. Several noticeable PGNAA peaks have been identified and are presented in Table 3. Most of these have been identified as background lines from the container (iron lines) and possible the plastic bags (chlorine lines), although the chlorine might also be present as a contaminant in the yellowcake itself resulting from its manufacture.[18] 


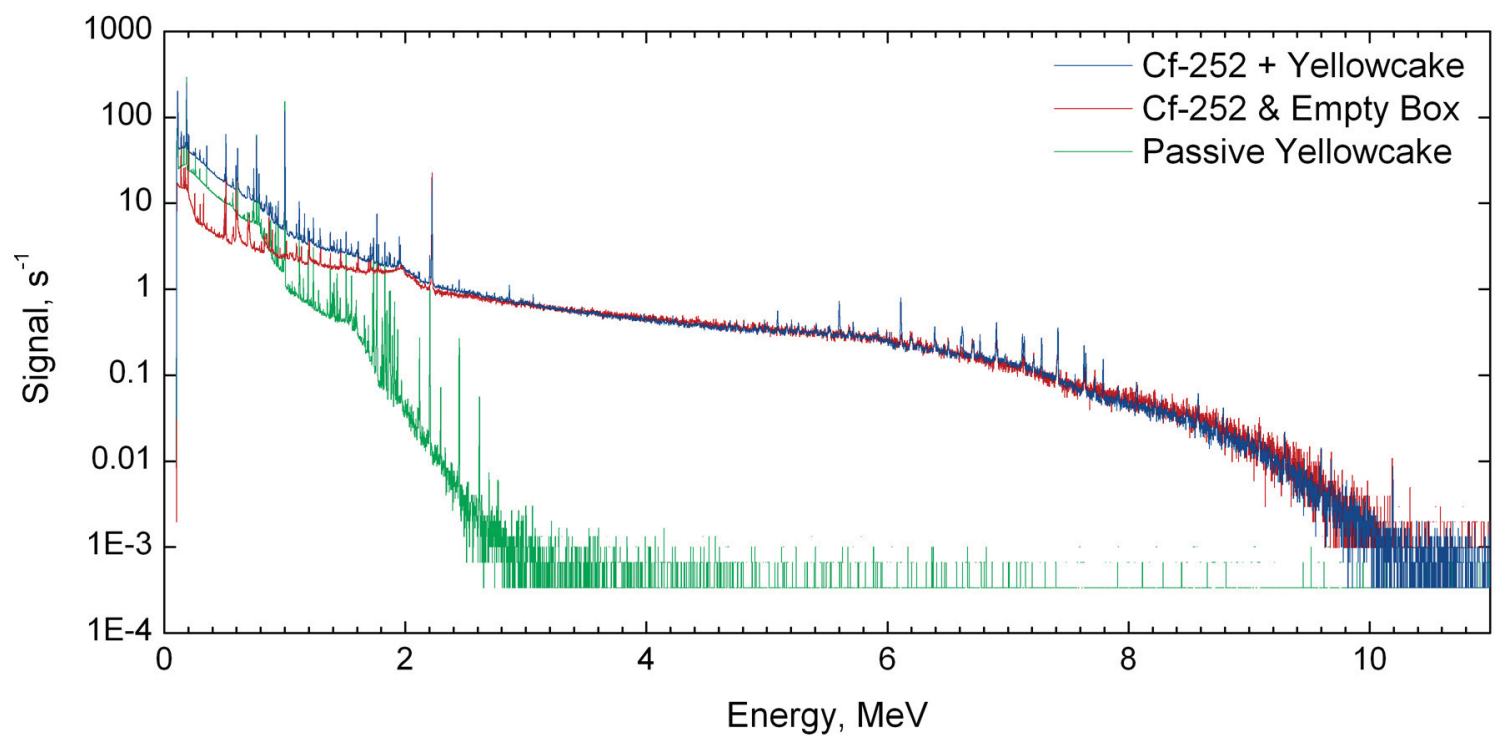

Figure 4 The passive gamma-ray spectra from a sample of natural-enrichment yellowcake in the moderated polyethylene box (measured for 3000 livetime seconds, green), the PGNAA response of that sample using a ${ }^{252} \mathrm{Cf}$ source (measured for 3000 livetime seconds, blue), and the PGNAA response of the empty box (measured for 3000 livetime seconds, red). 

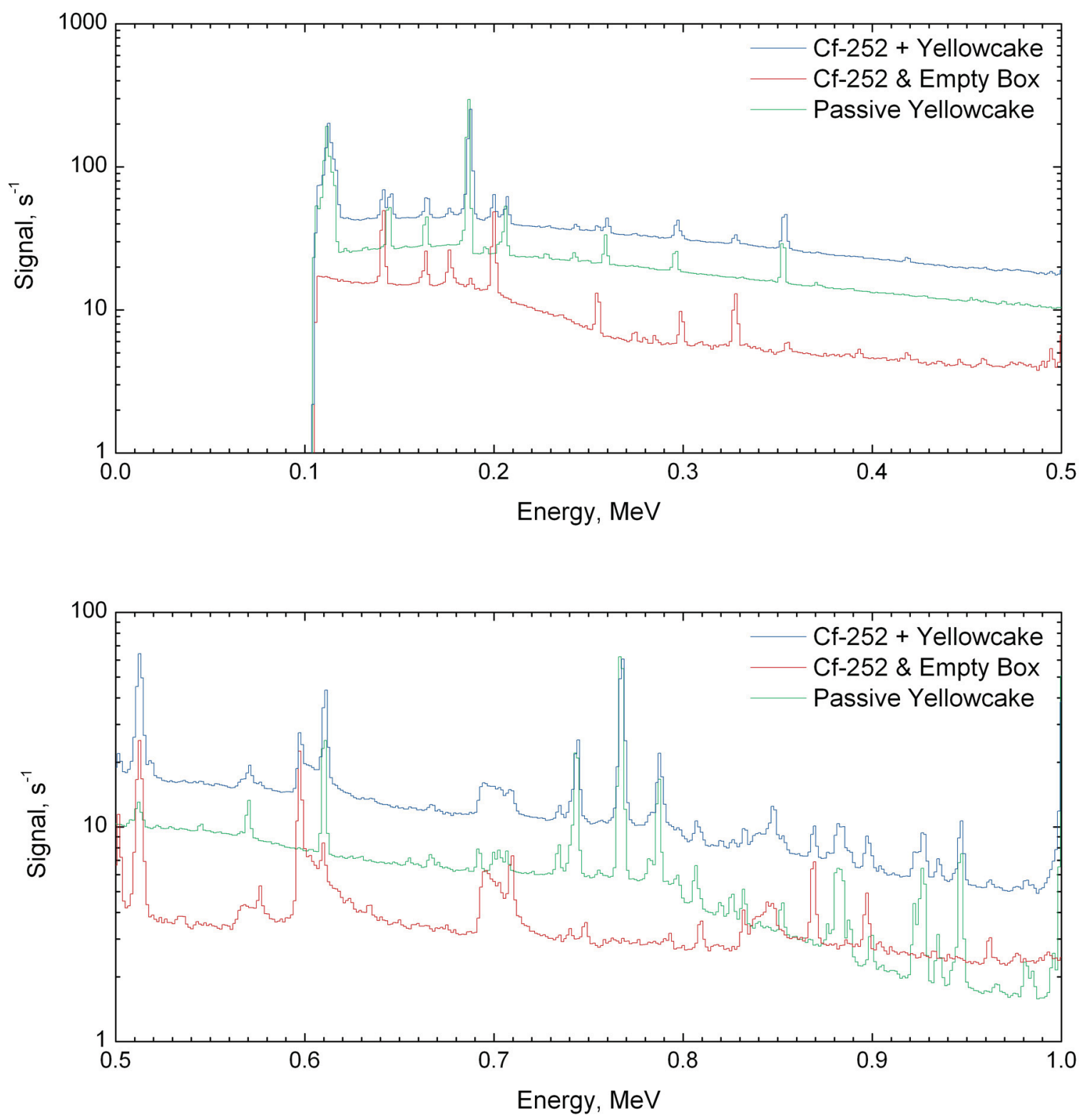

Figure 5 The passive and active neutron interrogation gamma-ray spectra of a yellowcake sample and the active background spectrum, as described in Figure 4; $0-0.5 \mathrm{MeV}$ and $0.5-1.0 \mathrm{MeV}$. 

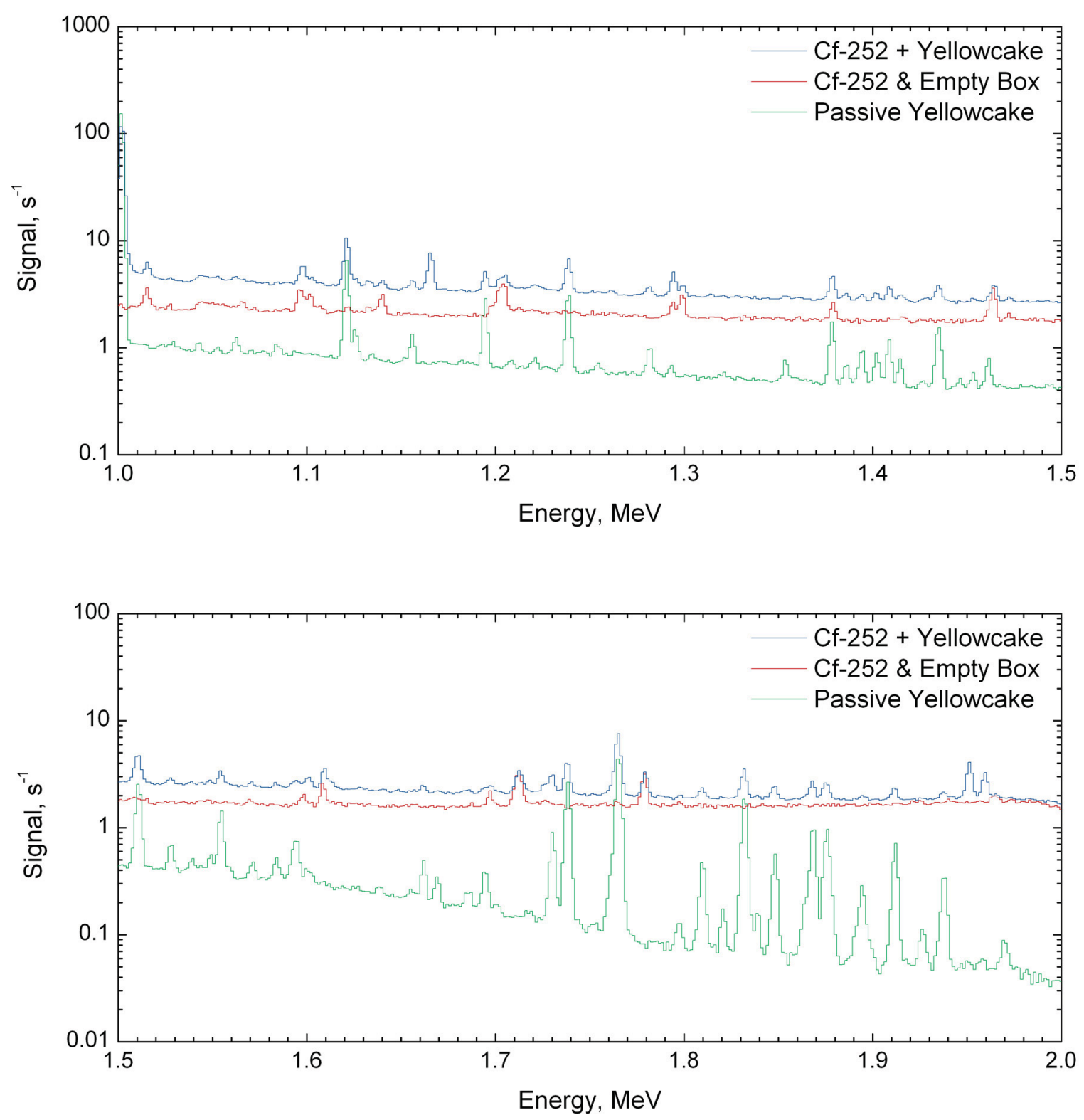

Figure 6 The passive and active neutron interrogation gamma-ray spectra of a yellowcake sample and the active background spectrum, as described in Figure 4; 1.0 - 1.5 MeV and 1.5-2.0 MeV. 

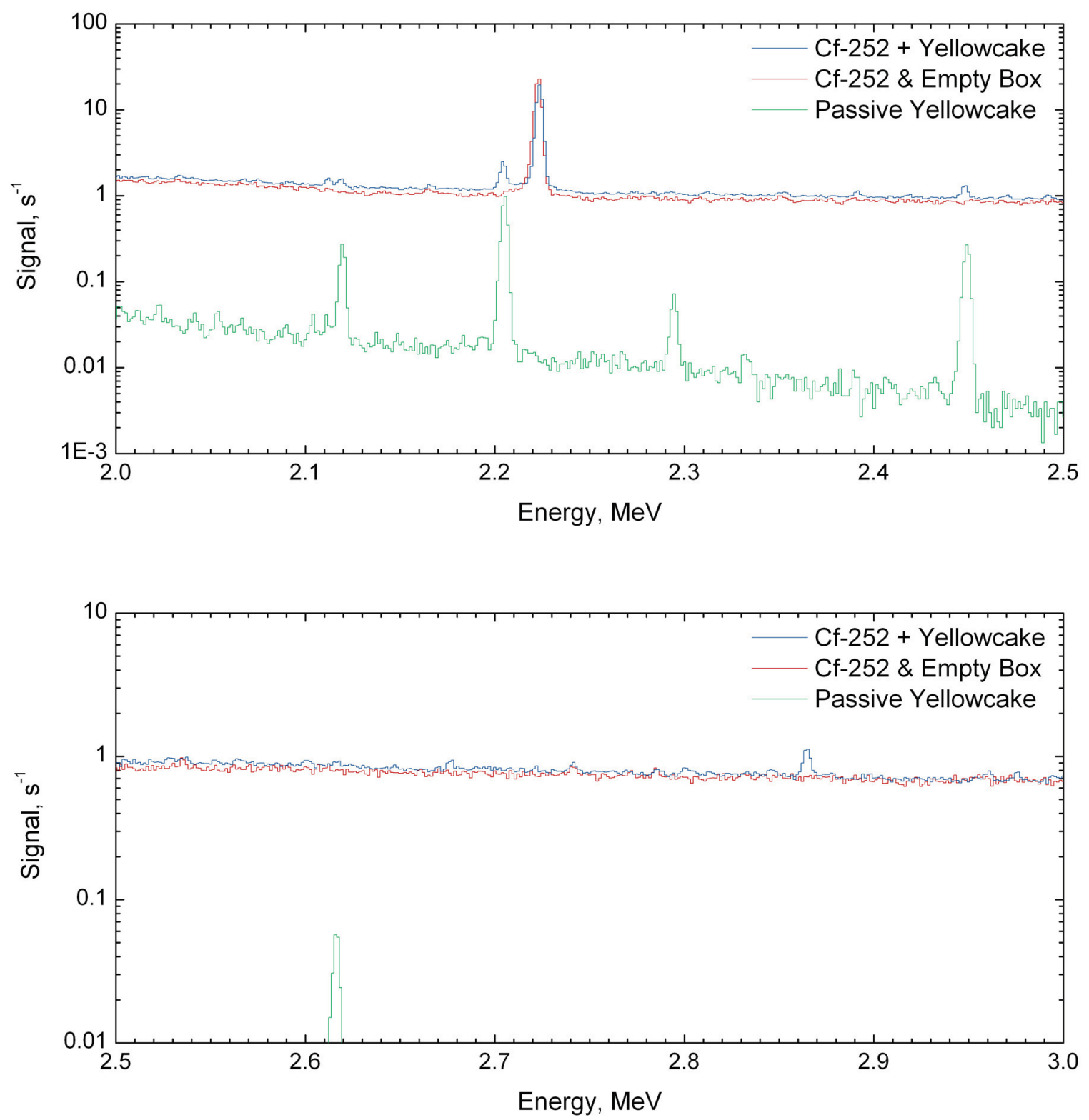

Figure 7 The passive and active neutron interrogation gamma-ray spectra of a yellowcake sample and the active background spectrum, as described in Figure 4; $2.0-2.5 \mathrm{MeV}$ and $2.5-3.0 \mathrm{MeV}$. 



Figure 8 The passive and active neutron interrogation gamma-ray spectra of a yellowcake sample and the active background spectrum, as described in Figure 4; 3.0 - 3.5 MeV and 3.5-4.0 MeV. 

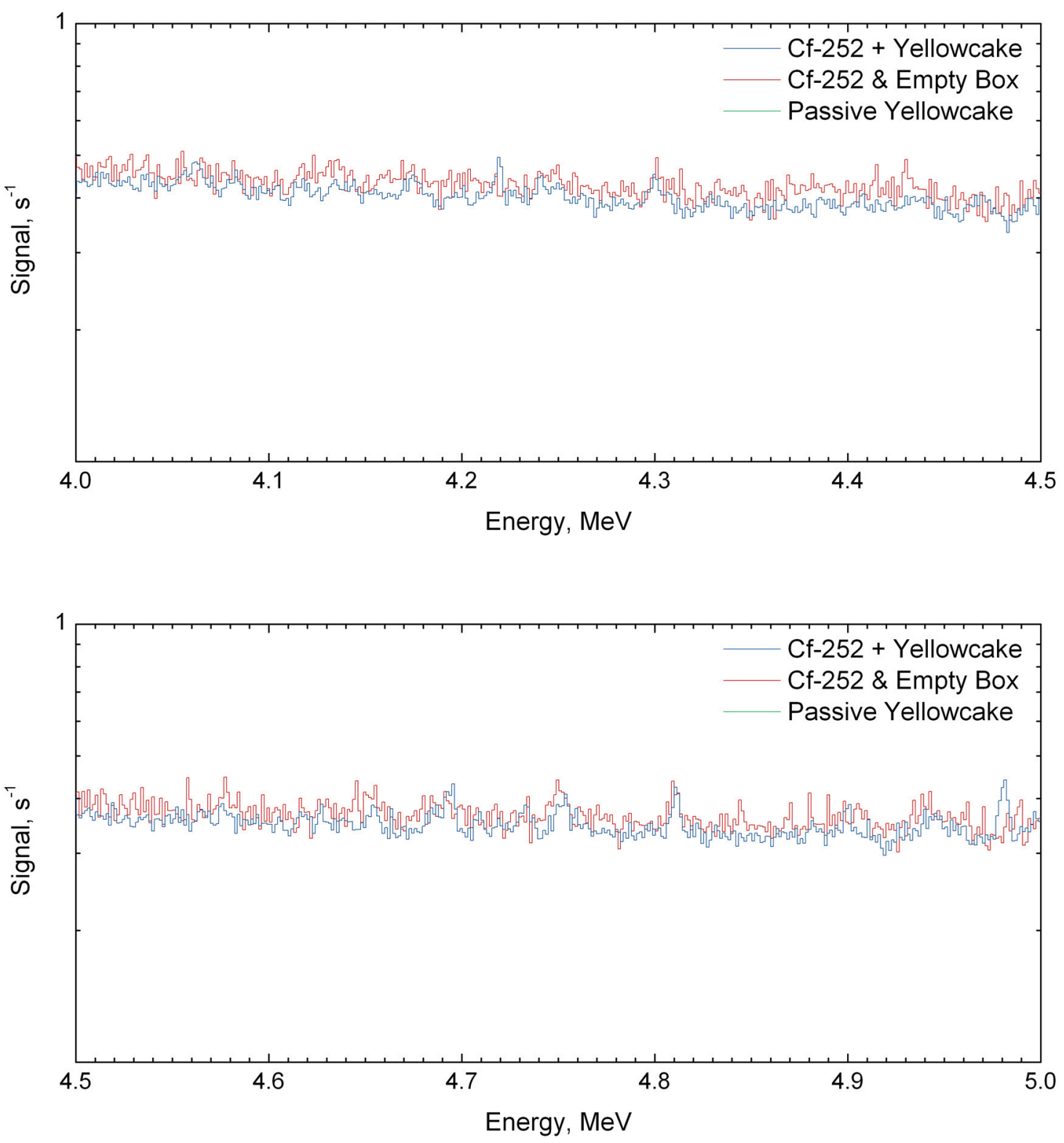

Figure 9 The passive and active neutron interrogation gamma-ray spectra of a yellowcake sample and the active background spectrum, as described in Figure 4; 4.0 - 4.5 MeV and 4.5 - 5.0 MeV. 

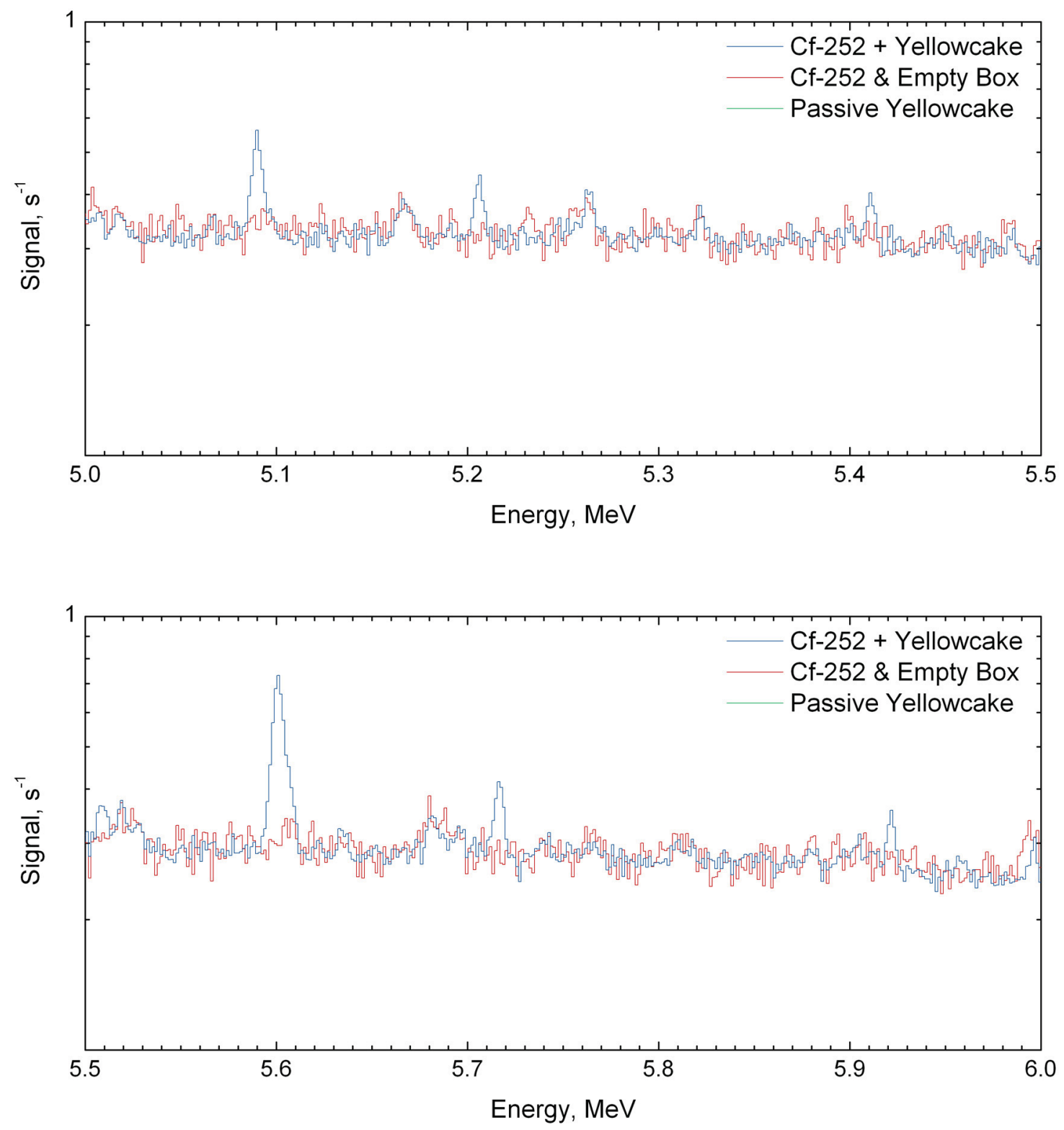

Figure 10 The passive and active neutron interrogation gamma-ray spectra of a yellowcake sample and the active background spectrum, as described in Figure 4; 5.0 - 5.5 MeV and 5.5-6.0 MeV. 

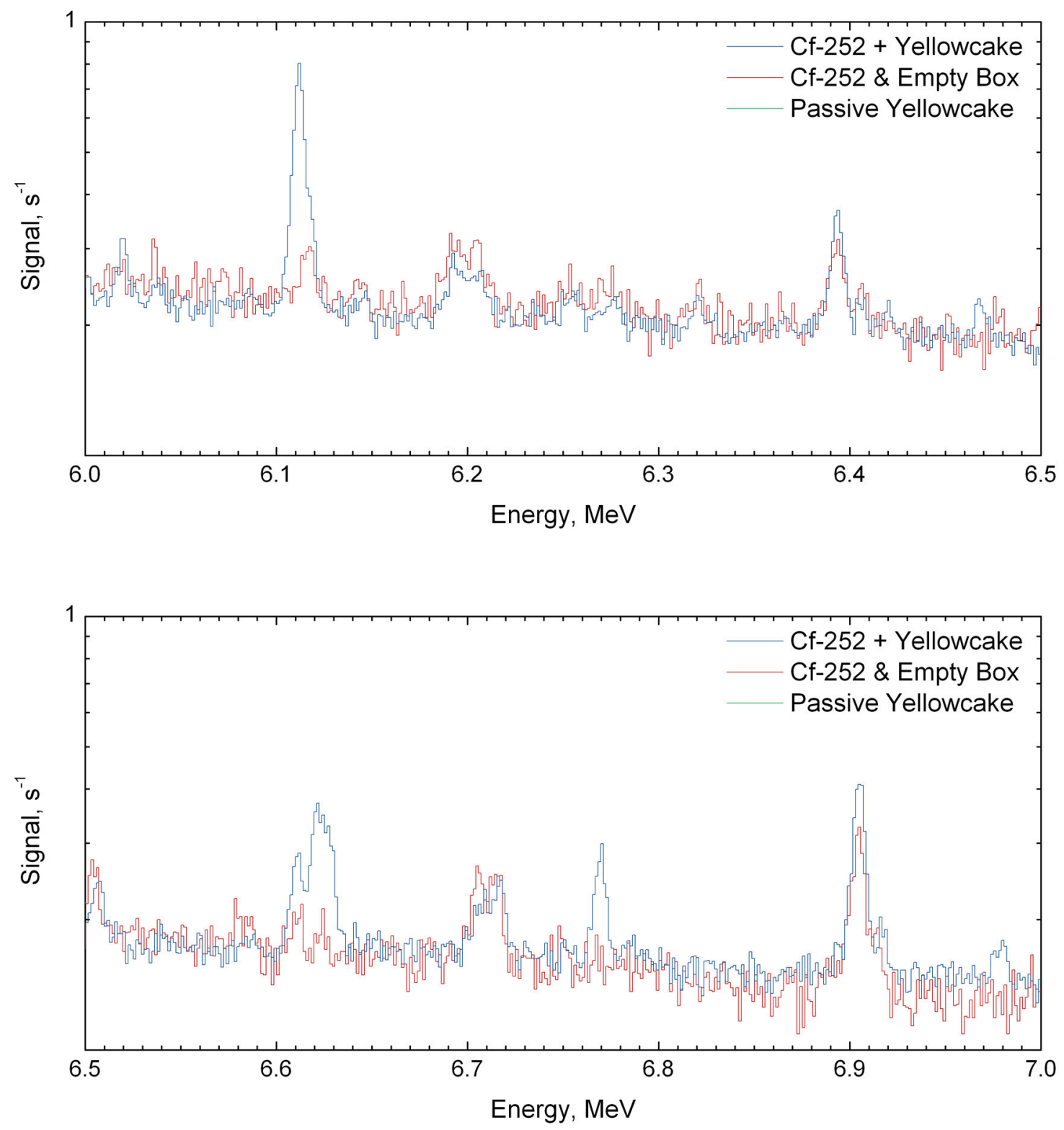

Figure 11 The passive and active neutron interrogation gamma-ray spectra of a yellowcake sample and the active background spectrum, as described in Figure 4; 6.0 - 6.5 MeV and 6.5 - 7.0 MeV. 

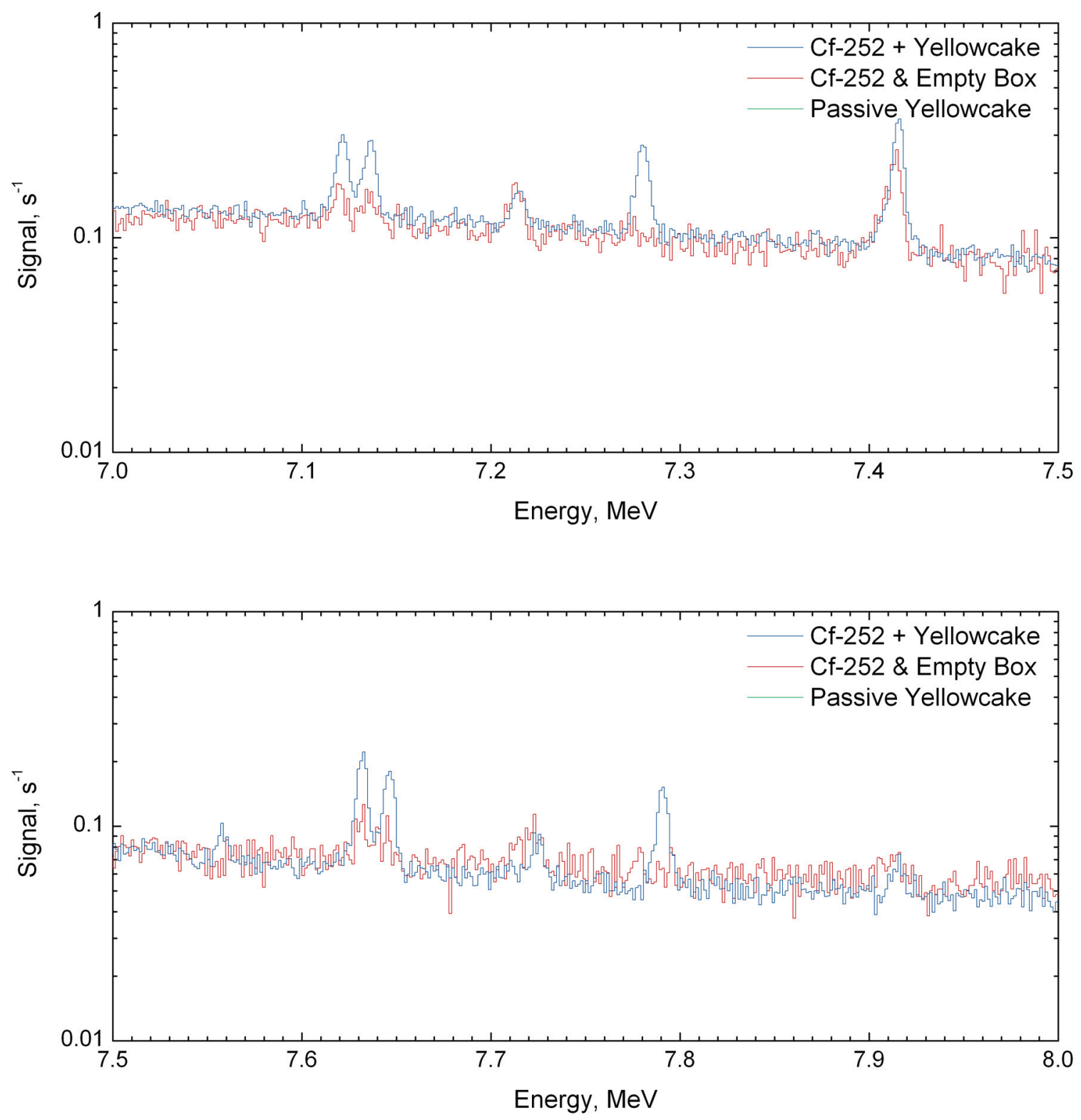

Figure 12 The passive and active neutron interrogation gamma-ray spectra of a yellowcake sample and the active background spectrum, as described in Figure 4; 7.0 - 7.5 MeV and 7.5 - 8.0 MeV. 

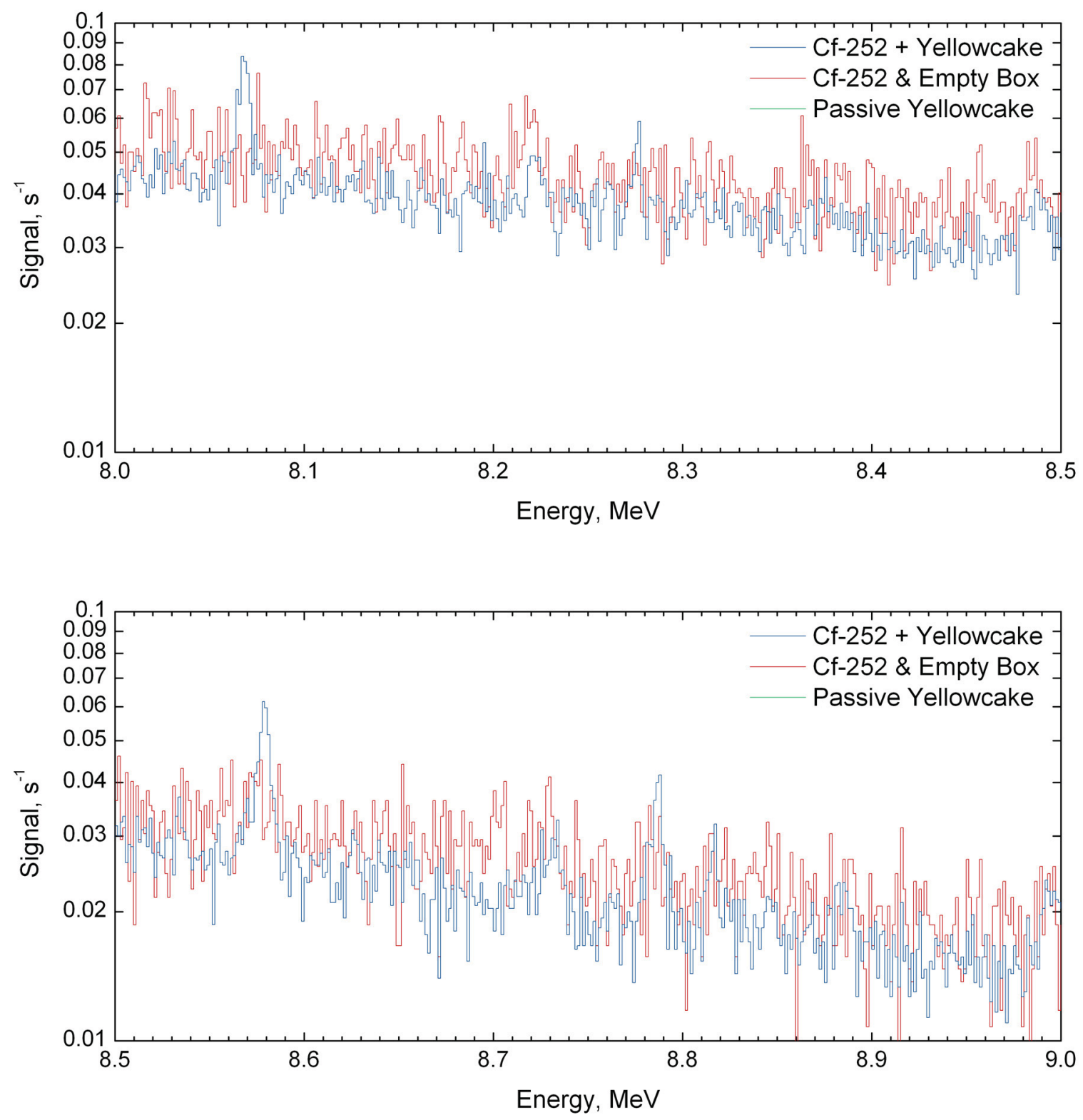

Figure 13 The passive and active neutron interrogation gamma-ray spectra of a yellowcake sample and the active background spectrum, as described in Figure 4; 8.0 - 8.5 MeV and 8.5-9.0 MeV. 

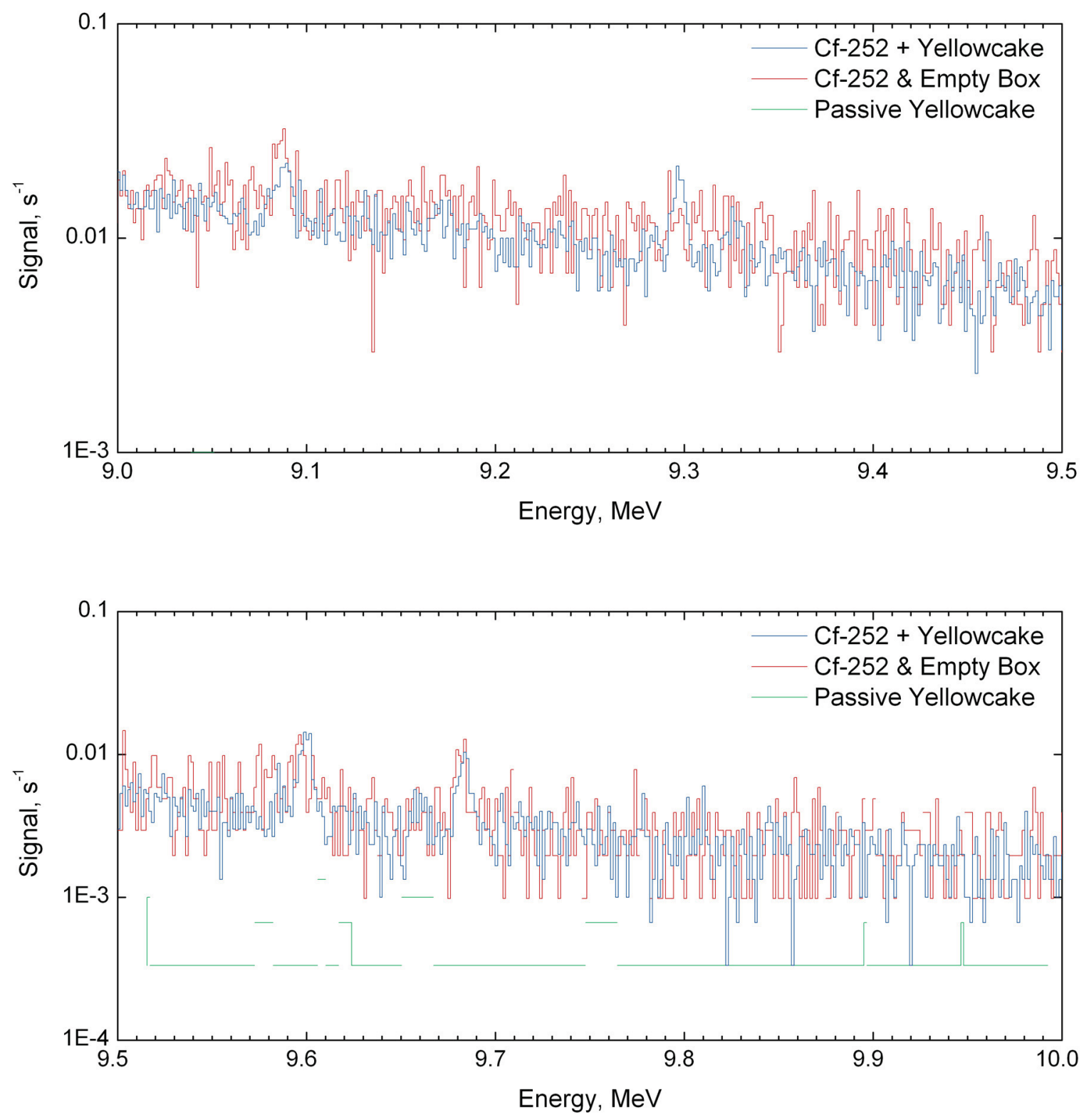

Figure 14 The passive and active neutron interrogation gamma-ray spectra of a yellowcake sample and the active background spectrum, as described in Figure 4; 9.0 - 9.5 MeV and 9.5-10.0 MeV. 

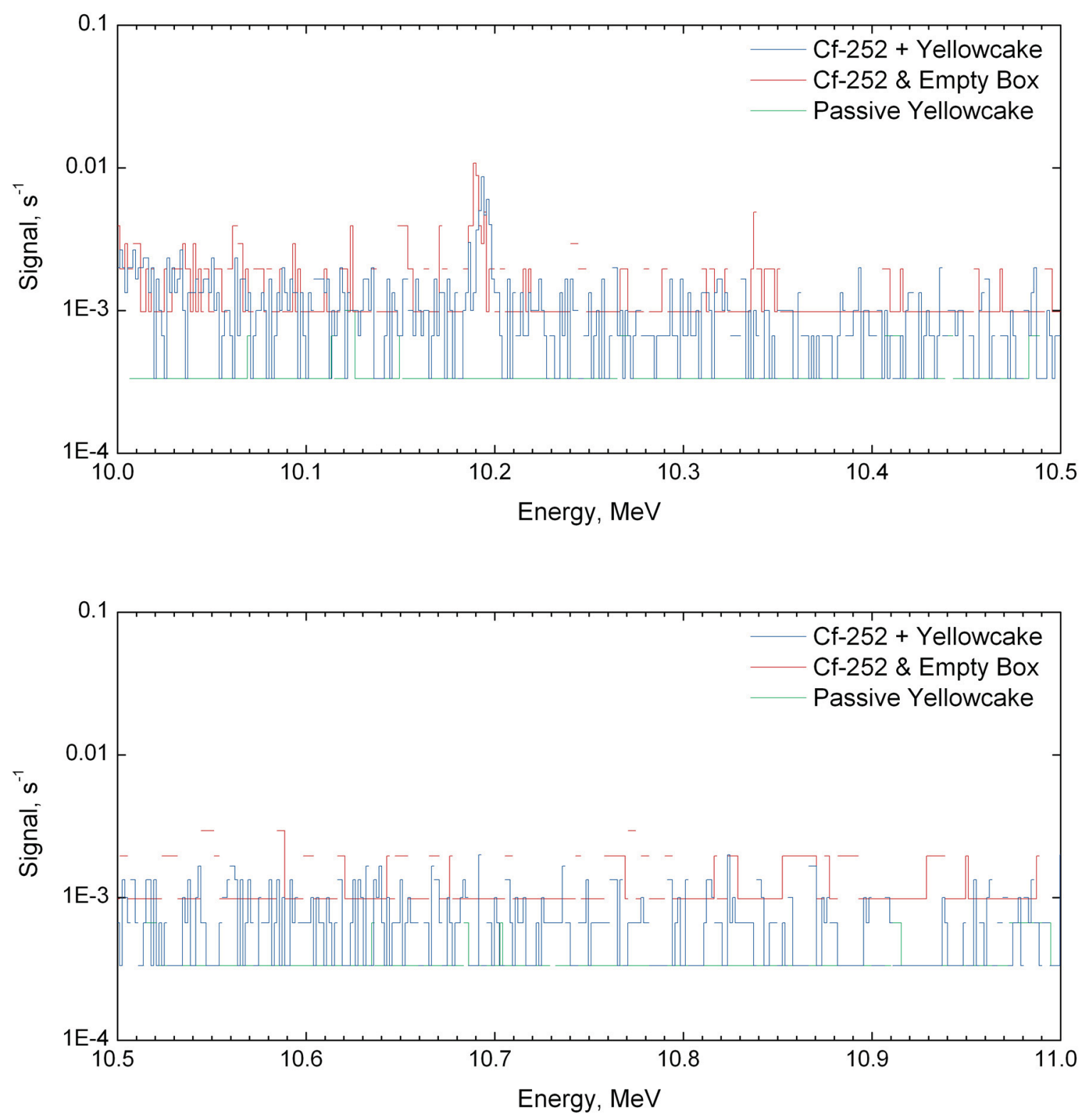

Figure 15 The passive and active neutron interrogation gamma-ray spectra of a yellowcake sample and the active background spectrum, as described in Figure $4 ; 10.0-10.5 \mathrm{MeV}$ and $10.5-11.0 \mathrm{MeV}$. 
Table 3 Notable PGNAA products observed in the irradiation of the yellowcake sample.

\begin{tabular}{|c|c|}
\hline $\begin{array}{l}\text { Energy } \\
{[\mathrm{MeV}]}\end{array}$ & Likely Activation Products \\
\hline 1.164 & ${ }^{38} \mathrm{Cl}(1.165 \mathrm{MeV})$ \\
\hline 1.951 & ${ }^{38} \mathrm{Cl}(1.951 \mathrm{MeV})$ \\
\hline 1.959 & ${ }^{38} \mathrm{Cl}(1.959 \mathrm{MeV})$ \\
\hline 2.112 & ${ }^{56,57} \mathrm{Fe}(2.113 \mathrm{MeV})$ \\
\hline 2.863 & ${ }^{36} \mathrm{Cl}(2863 \mathrm{MeV})$ \\
\hline 3.062 & ${ }^{56} \mathrm{Fe},{ }^{59} \mathrm{Ni}(3063 \mathrm{MeV})$ \\
\hline 4.218 & $\mathrm{Fe}$ \\
\hline 4.981 & Not yet determined \\
\hline 5.089 & $2^{\text {nd }}$ escape peak \\
\hline 5.206 & $1^{\text {st }}$ escape peak \\
\hline 5.410 & $1^{\text {st }}$ escape peak \\
\hline 5.507 & $1^{\text {st }}$ escape peak \\
\hline 5.600 & $1^{\text {st }}$ escape peak \\
\hline 5.716 & Not yet determined \\
\hline 5.921 & ${ }^{57} \mathrm{Fe}(5.920 \mathrm{MeV})$ \\
\hline 6.018 & $\mathrm{Fe}$ \\
\hline 6.111 & ${ }^{38} \mathrm{Cl}(6.111 \mathrm{MeV})$ \\
\hline 6.467 & $1^{\text {st }}$ escape peak \\
\hline 6.611 & $2^{\text {nd }}$ escape peak \\
\hline 6.621 & $2^{\text {nd }}$ escape peak \\
\hline 6.769 & Not yet determined \\
\hline 6.979 & Not yet determined \\
\hline 7.121 & $1^{\text {st }}$ escape peak \\
\hline 7.136 & $1^{\text {st }}$ escape peak \\
\hline 7.281 & $\mathrm{Fe}$ \\
\hline 7.557 & Not yet determined \\
\hline 7.632 & ${ }^{57} \mathrm{Fe}(7.631 \mathrm{MeV})$ \\
\hline 7.646 & ${ }^{57} \mathrm{Fe}(7.645 \mathrm{MeV})$ \\
\hline 7.790 & Not yet determined \\
\hline 8.068 & $1^{\text {st }}$ escape peak \\
\hline 8.579 & Not yet determined \\
\hline 9.297 & $\mathrm{Fe}$ \\
\hline
\end{tabular}

\section{Bulk NAA - Natural Enrichment Yellowcake}

To complement the PGNAA data taken of the yellowcake $\left({ }^{238} \mathrm{U}\right)$ a traditional neutron active analysis (NAA) data set was also taken of the yellowcake following removal of the ${ }^{252} \mathrm{Cf}$ neutron source. This measurement sought to determine if any shortlive fission product or activation products could be identified in the post-irradiation yellowcake. This data is shown in Figure 16 for the complete $0-11 \mathrm{MeV}$ gamma ray range and then in Figure 17 through Figure 19 for successive $0.5-\mathrm{MeV}$ regions of interest. Several NAA peaks have been identified and are presented in Table 4. A few of these have been identified as background lines from the container (iron lines) and possibly the 
plastic bags (chlorine lines) but further work is needed to resolve the remaining as-yet unidentified lines.



Figure 16 The passive gamma-ray spectra from a sample of natural-enrichment yellowcake (measured for 3000 livetime seconds, green) and the same sample following irradiation for 3000 seconds in a polyethylene moderated box using a 3.3 microgram ${ }^{252} \mathrm{Cf}$ source neutron source (measured for 1000 livetime seconds, blue). 

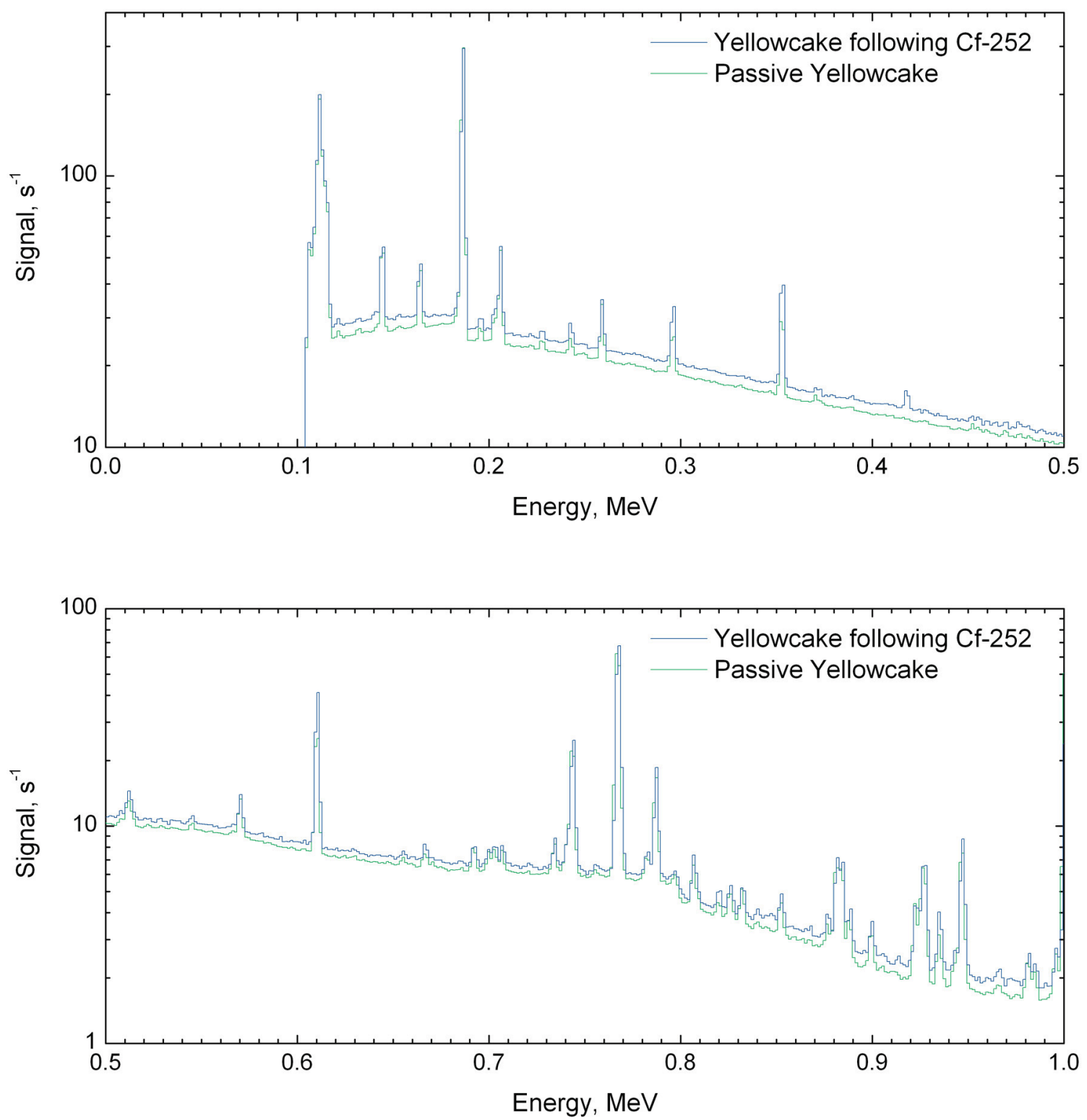

Figure 17 The passive cold and post-activation gamma-ray spectra of a yellowcake sample, as described in Figure 16; 0 - 0.5 MeV and 0.5 - 1.0 MeV. 

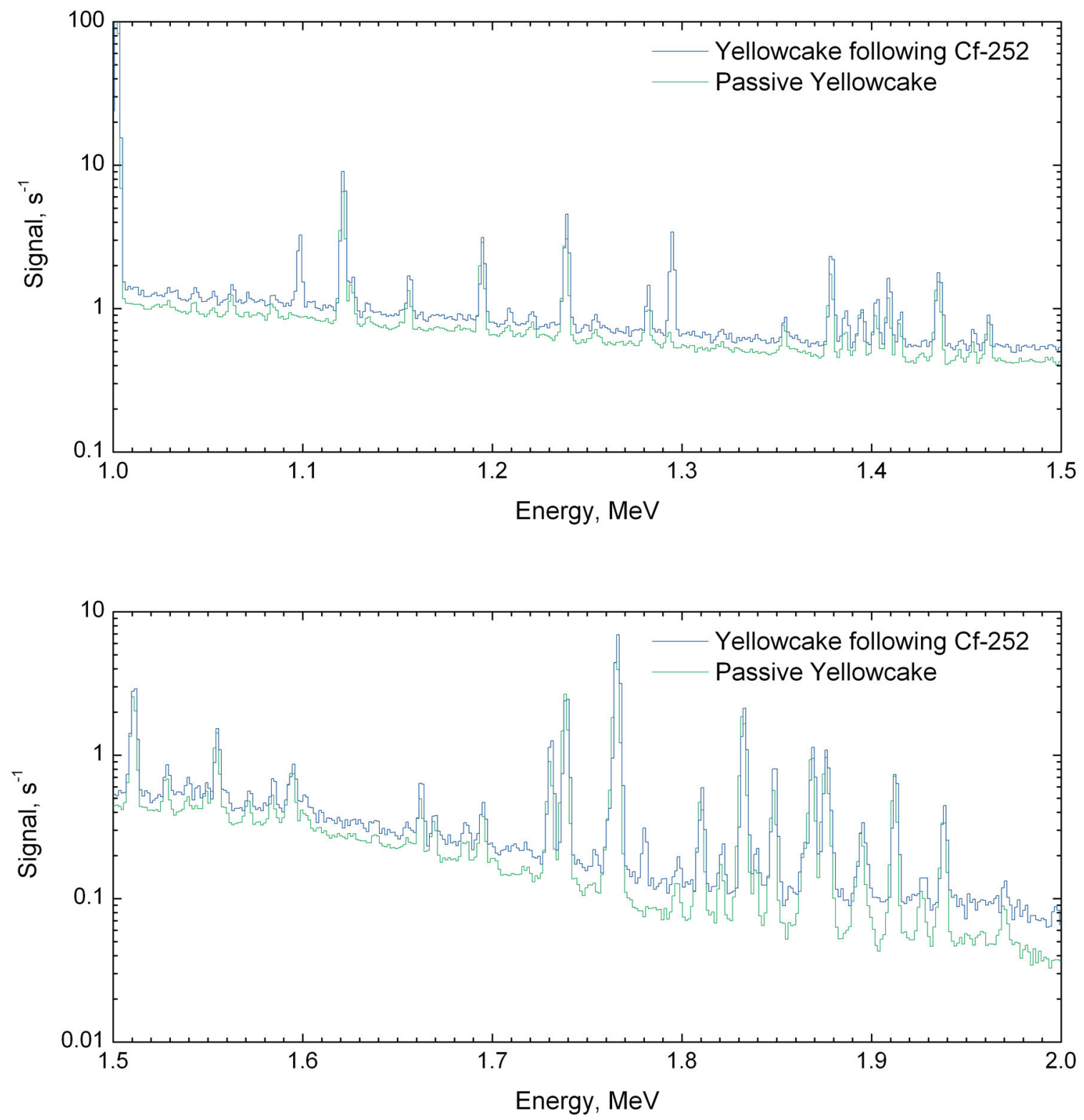

Figure 18 The passive cold and post-activation gamma-ray spectra of a yellowcake sample, as described in Figure 16; 1.0 - 1.5 MeV and 1.5 - 2.0 MeV. 

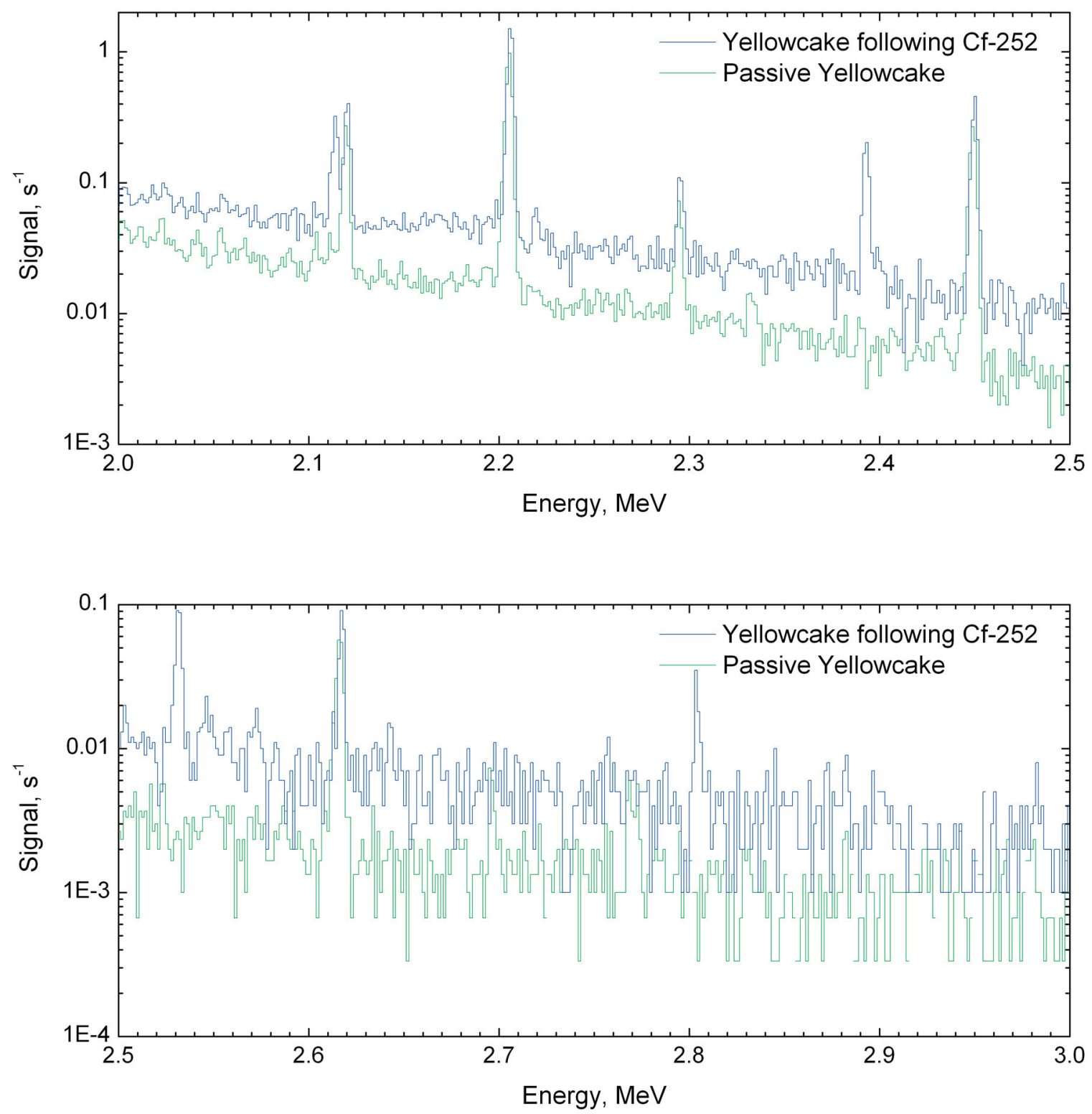

Figure 19 The passive cold and post-activation gamma-ray spectra of a yellowcake sample, as described in Figure 16; 2.0 - 2.5 MeV and 2.5 - 3.0 MeV. 
Table 4 Notable activation products observed in the post-irradiation yellowcake sample.

\begin{tabular}{|c|c|}
\hline $\begin{array}{c}\text { Energy } \\
{[\mathrm{MeV}]}\end{array}$ & Likely Activation Products \\
\hline 0.418 & Not yet determined \\
\hline 1.098 & ${ }^{59} \mathrm{Fe}(1.099 \mathrm{MeV})$ \\
\hline 1.294 & ${ }^{59} \mathrm{Fe}(1.292 \mathrm{MeV})$ \\
\hline 1.779 & ${ }^{28} \mathrm{Al}(1.779 \mathrm{MeV})$ \\
\hline 2.114 & Not yet determined \\
\hline 2.220 & Not yet determined \\
\hline 2.394 & Not yet determined \\
\hline 2.401 & Not yet determined \\
\hline 2.533 & Not yet determined \\
\hline 2.804 & Not yet determined \\
\hline
\end{tabular}

\section{PGNAA - Depleted Uranium Metal}

In Figure 20 data is presented showing the complete 0-11 MeV gamma-ray spectrum from DU irradiated in the unmoderated PINS geometry using the DD-ENG. Zoomed views of this data are shown in Figure 21 through Figure 26 for successive regions of interest. These plots show the passive HPGe spectrum of the DU metal prior to irradiation, the test environment's active-background PGNAA spectrum without the uranium sample, and the DU PGNNA spectrum. No distinguishable DU PGNAA lines were identified. 


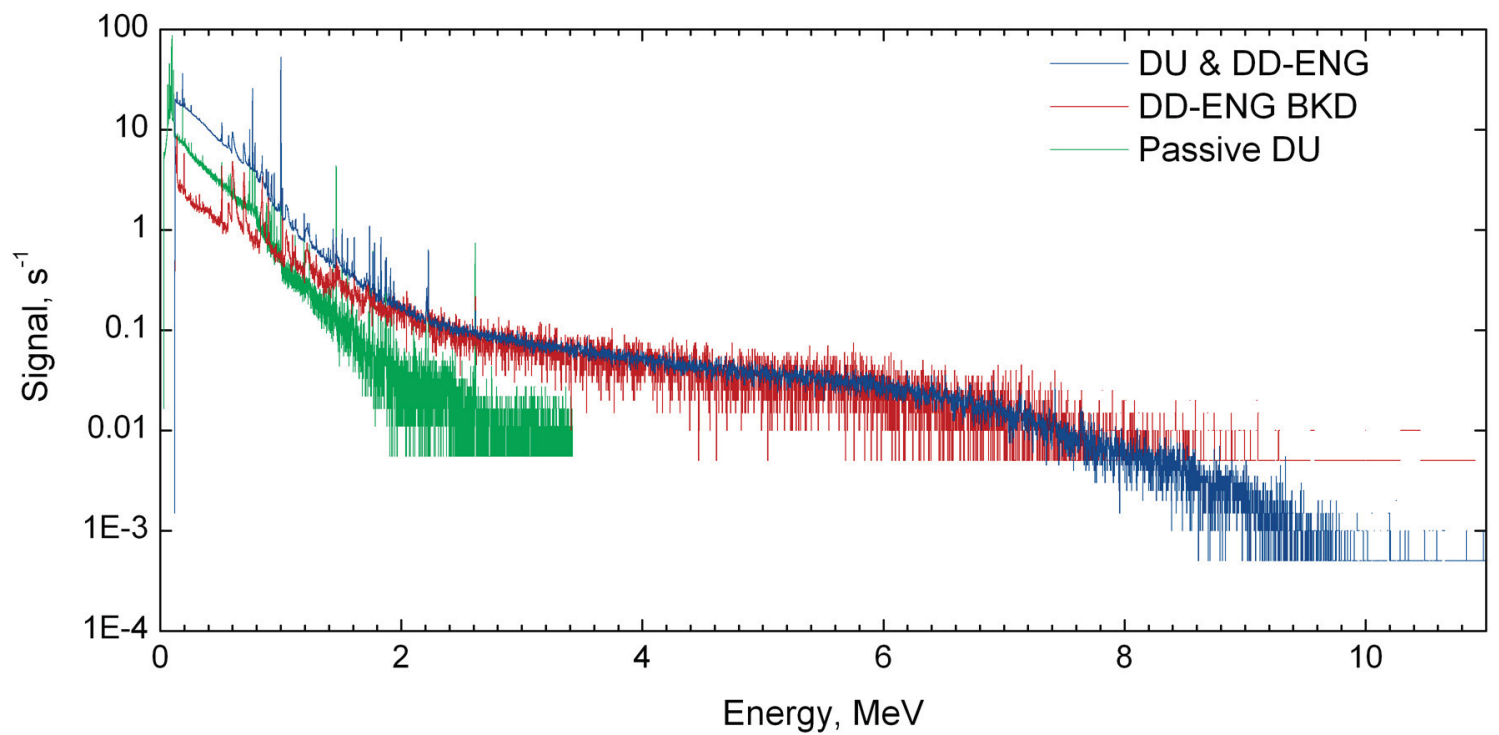

Figure 20 The passive gamma-ray spectra from a sample of depleted uranium (measured for 3600 livetime seconds, green), the PGNAA response of that sample using a DD-ENG neutron source (measured for 2000 livetime seconds, blue), and the PGNAA response of the empty test area (measured for 200 livetime seconds, red). 

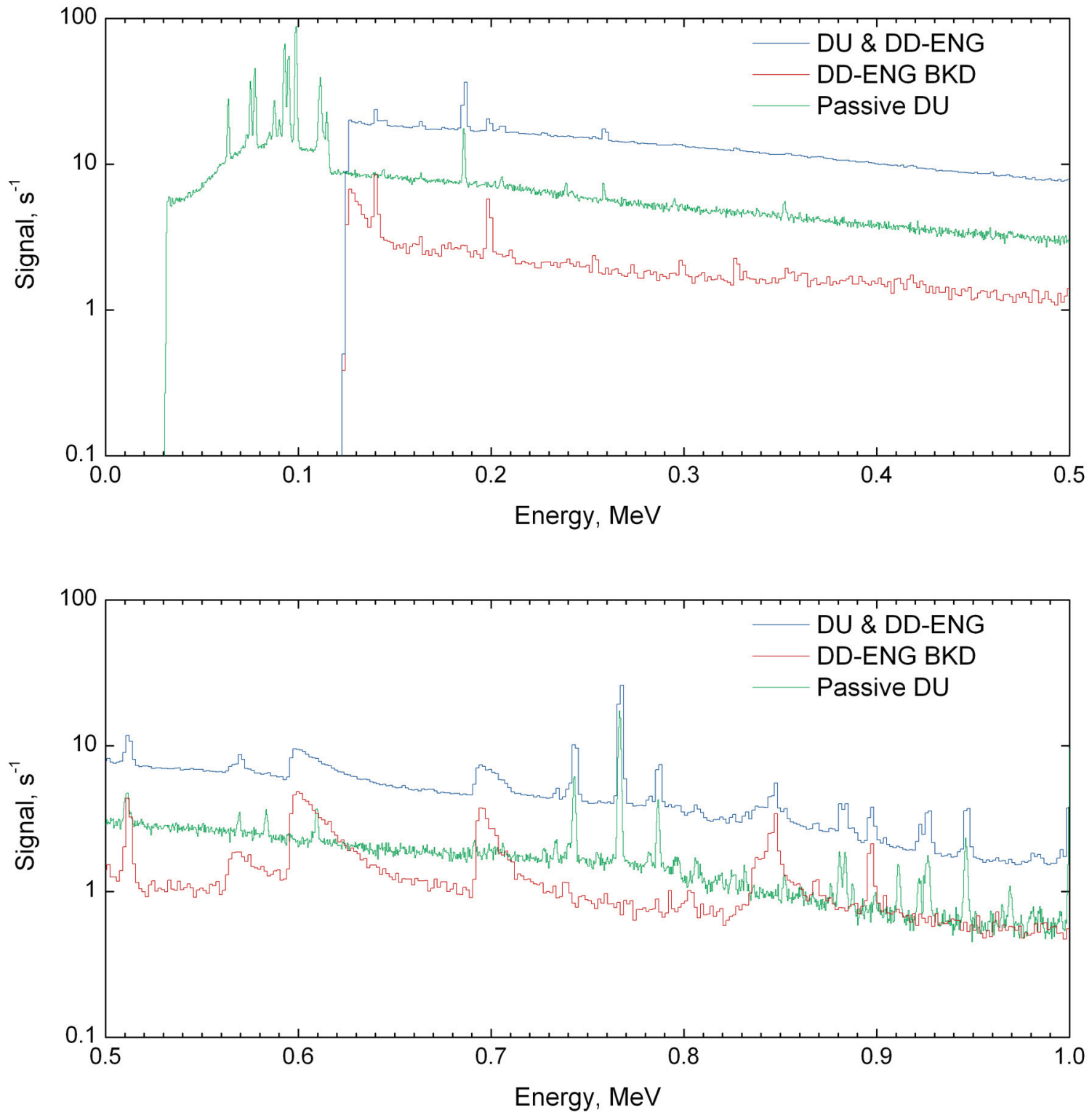

Figure 21 The passive, active, and active-background spectra for PGNAA measurements of depleted uranium, as described in Figure 20; $0-0.5 \mathrm{MeV}$ and $0.5-1.0 \mathrm{MeV}$. 

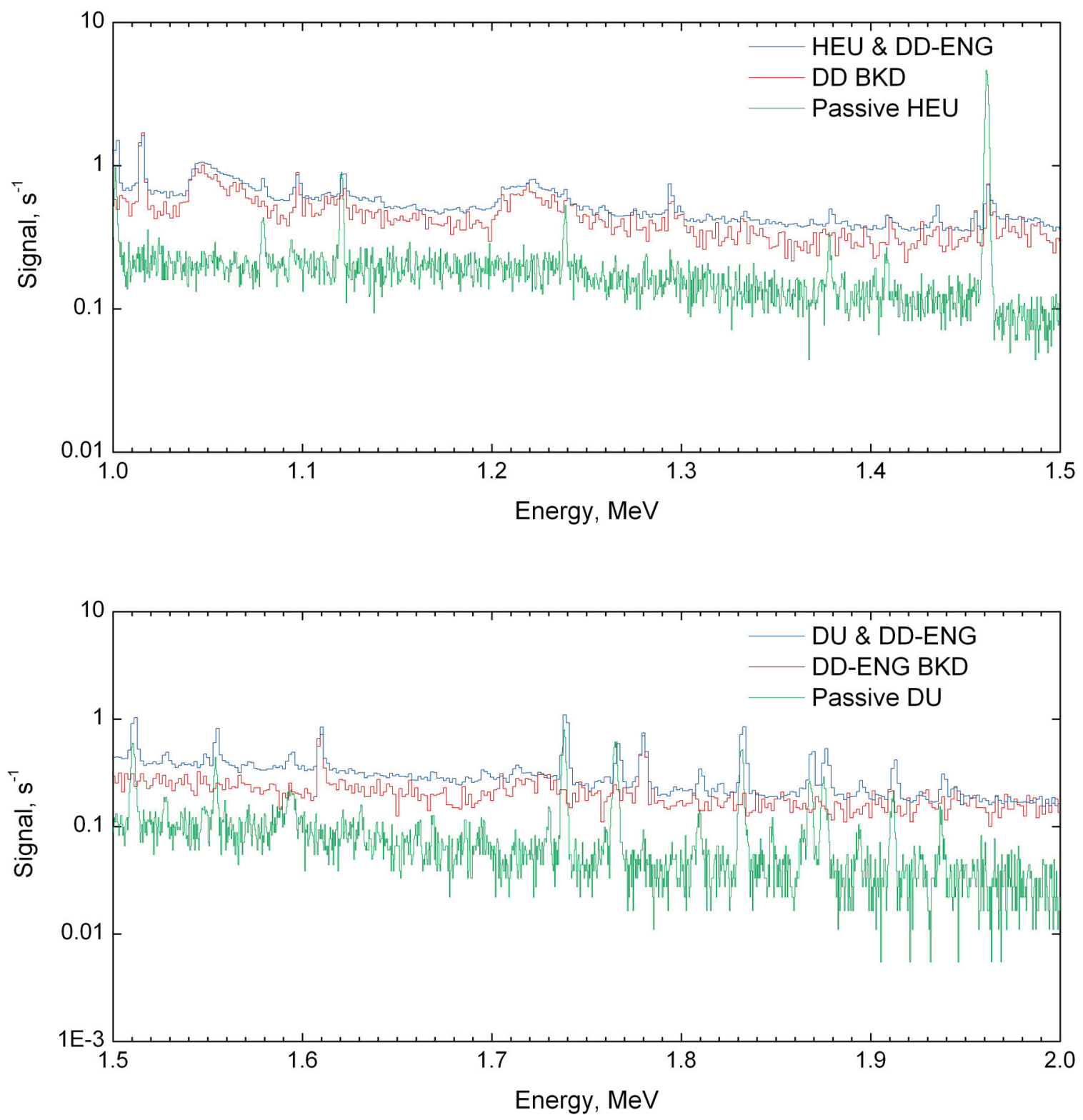

Figure 22 The passive, active, and active-background spectra for PGNAA measurements of depleted uranium, as described in Figure 20; 1.0 - 1.5 MeV and 1.5 - 2.0 MeV. 

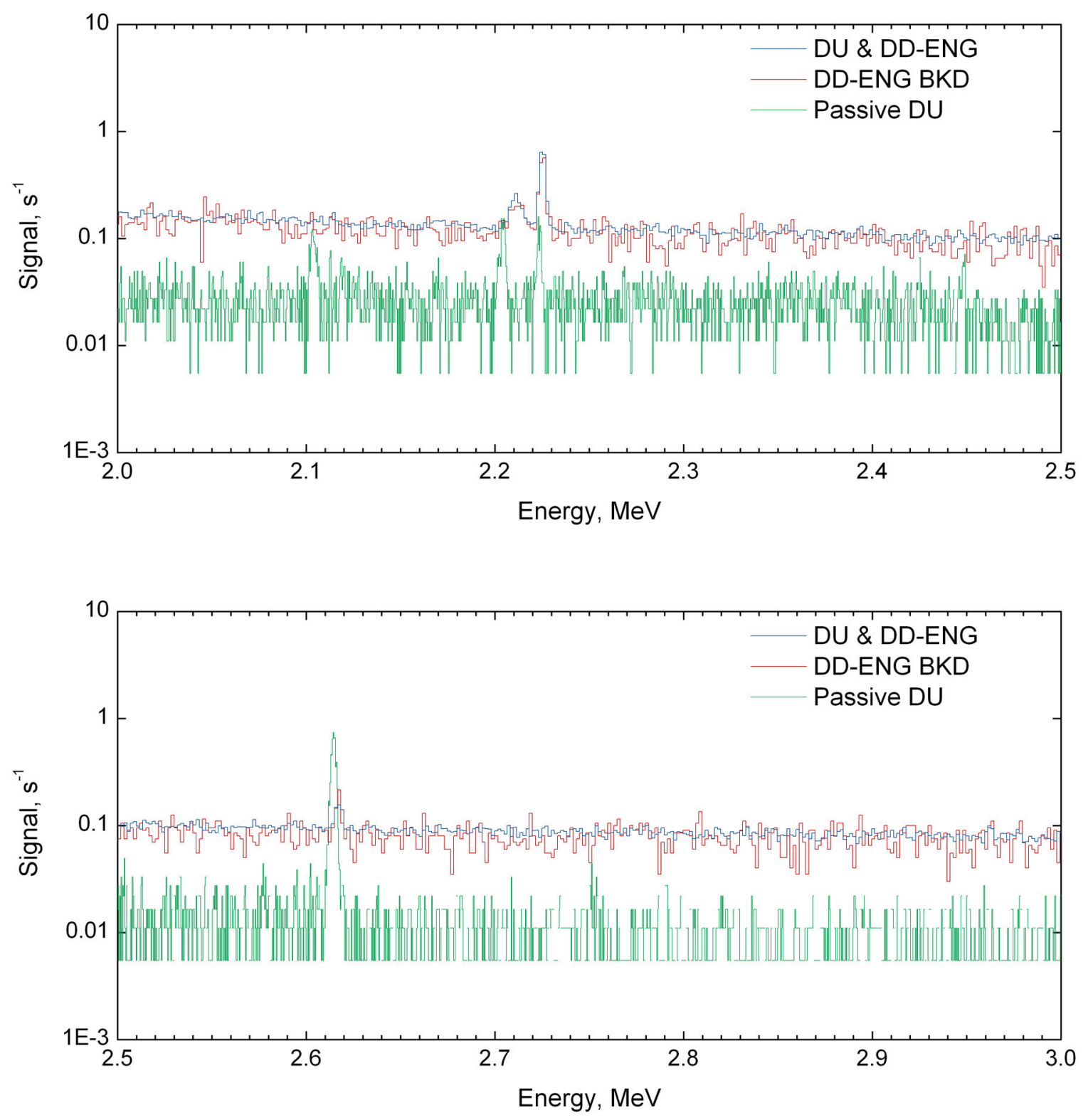

Figure 23 The passive, active, and active-background spectra for PGNAA measurements of depleted uranium, as described in Figure 20; 2.0 - 2.5 MeV and 2.5 - 3.0 MeV. 

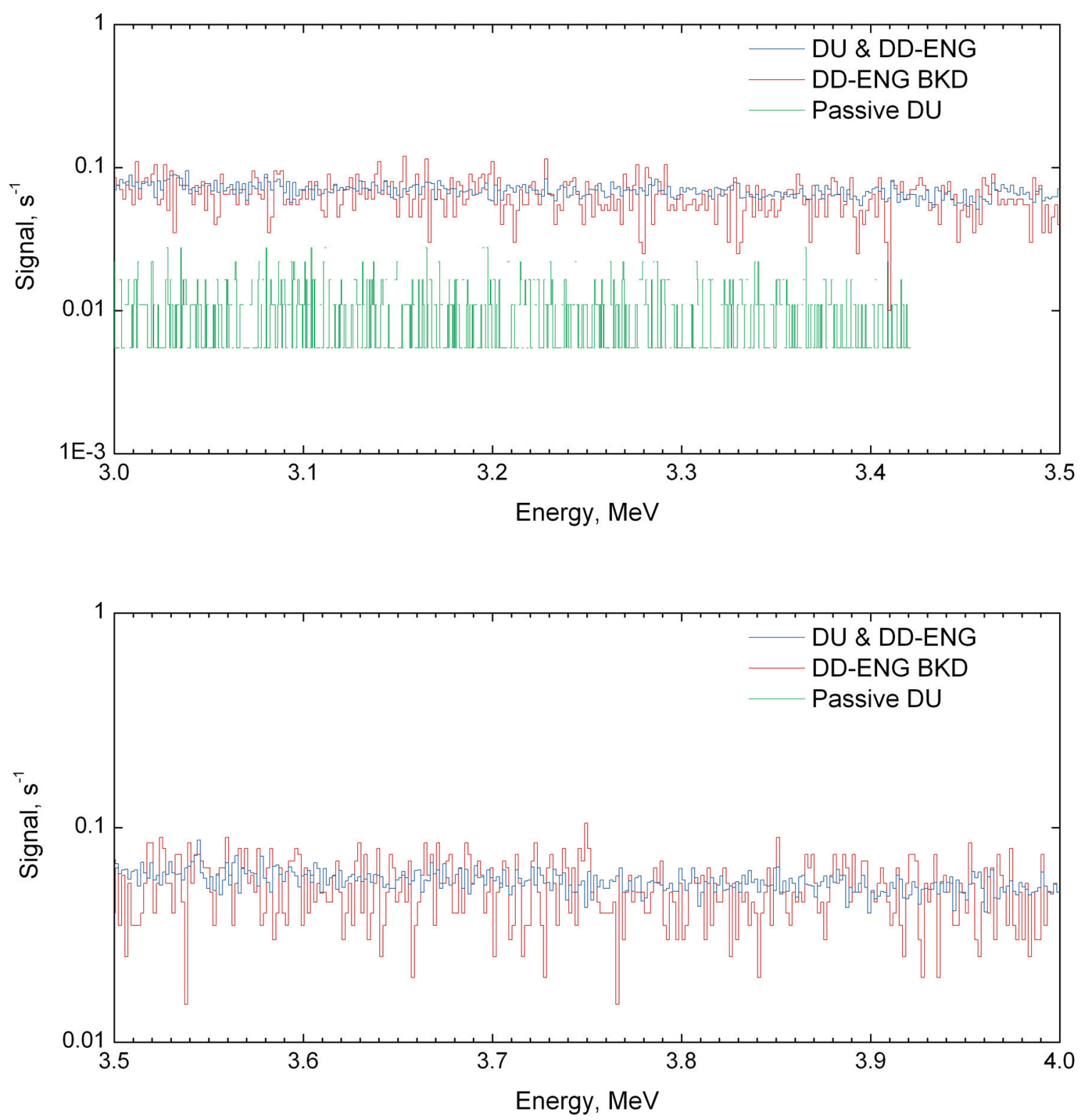

Figure 24 The passive, active, and active-background spectra for PGNAA measurements of depleted uranium, as described in Figure 20; 3.0 - 3.5 MeV and 3.5 - 4.0 MeV. 

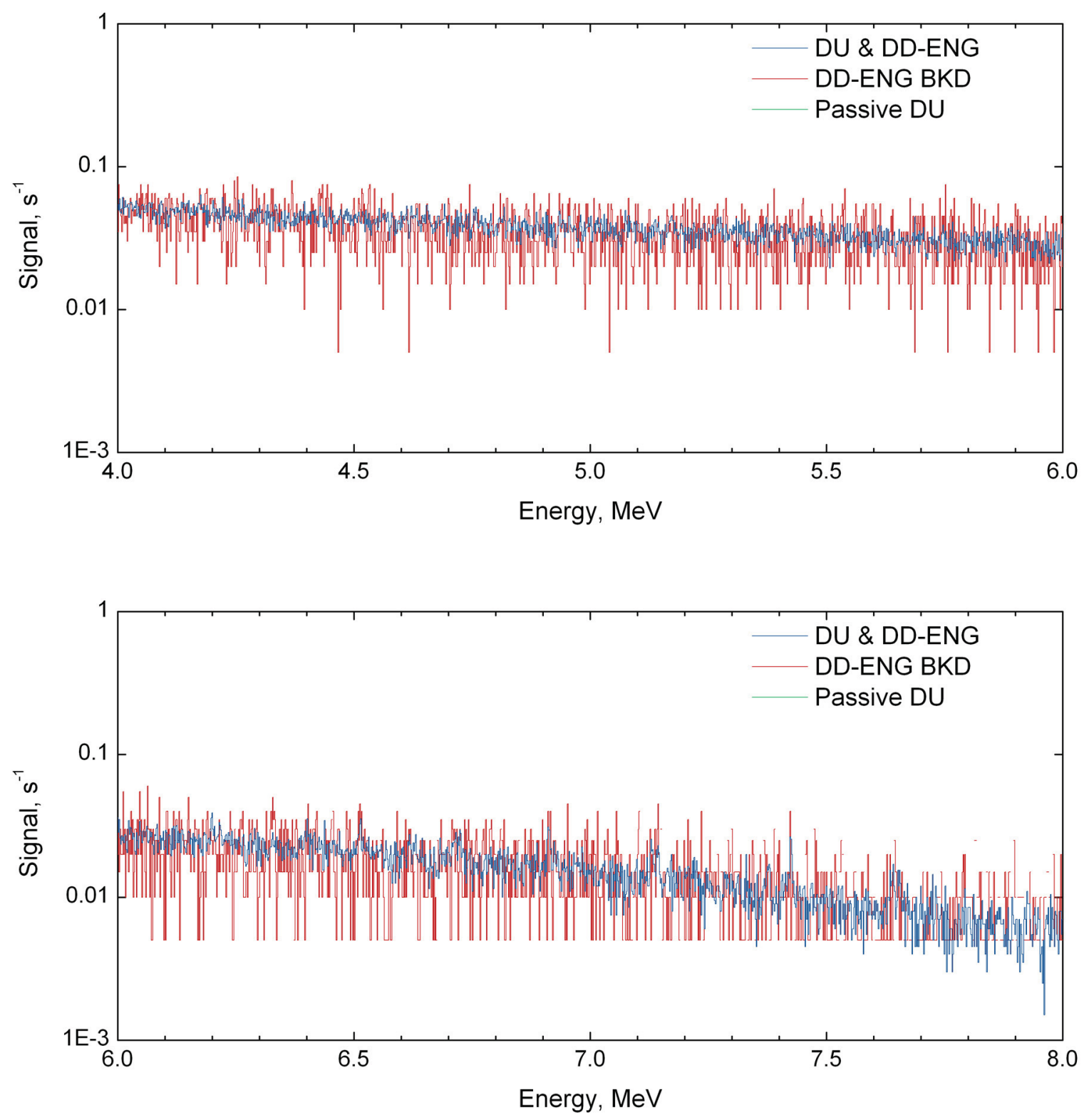

Figure 25 The passive, active, and active-background spectra for PGNAA measurements of depleted uranium, as described in Figure 20; 4.0 - 6.0 MeV and 6.0 - 8.0 MeV. 


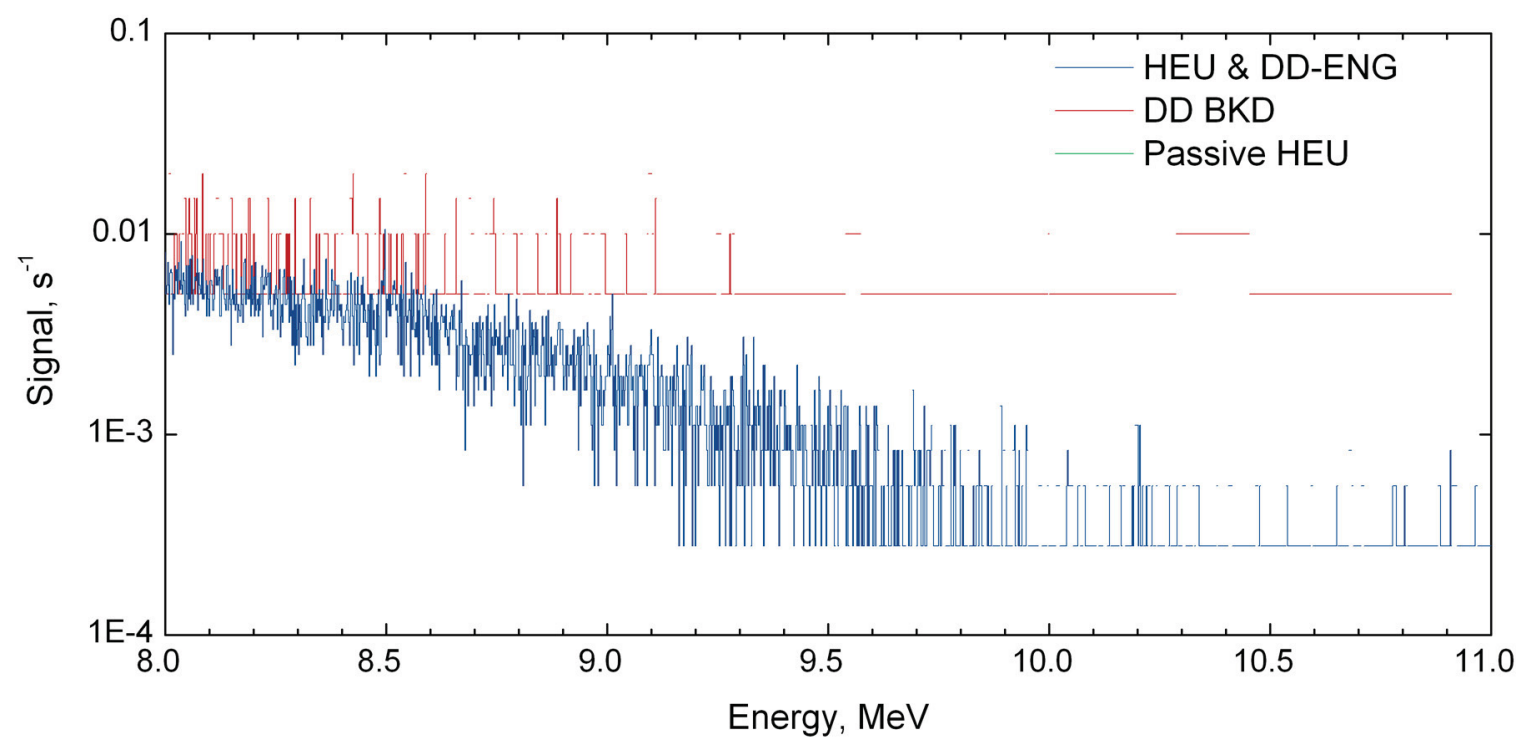

Figure 26 The passive, active, and active-background spectra for PGNAA measurements of depleted uranium, as described in Figure 20; 8.0 - 11.0 MeV. 


\section{PGNAA - Enriched Uranium Metal}

In Figure 27 data is presented showing the complete 0-11 MeV gamma-ray spectrum from HEU irradiated in the unmoderated PINS geometry using the DD-ENG. Zoomed views of this data are shown in Figure 28 through Figure 33 for successive regions of interest. These plots show the passive HPGe spectrum of the HEU metal prior to irradiation, the test environment's active-background PGNAA spectrum without the uranium sample, and the HEU PGNNA spectrum. No distinguishable HEU PGNAA lines were identified.

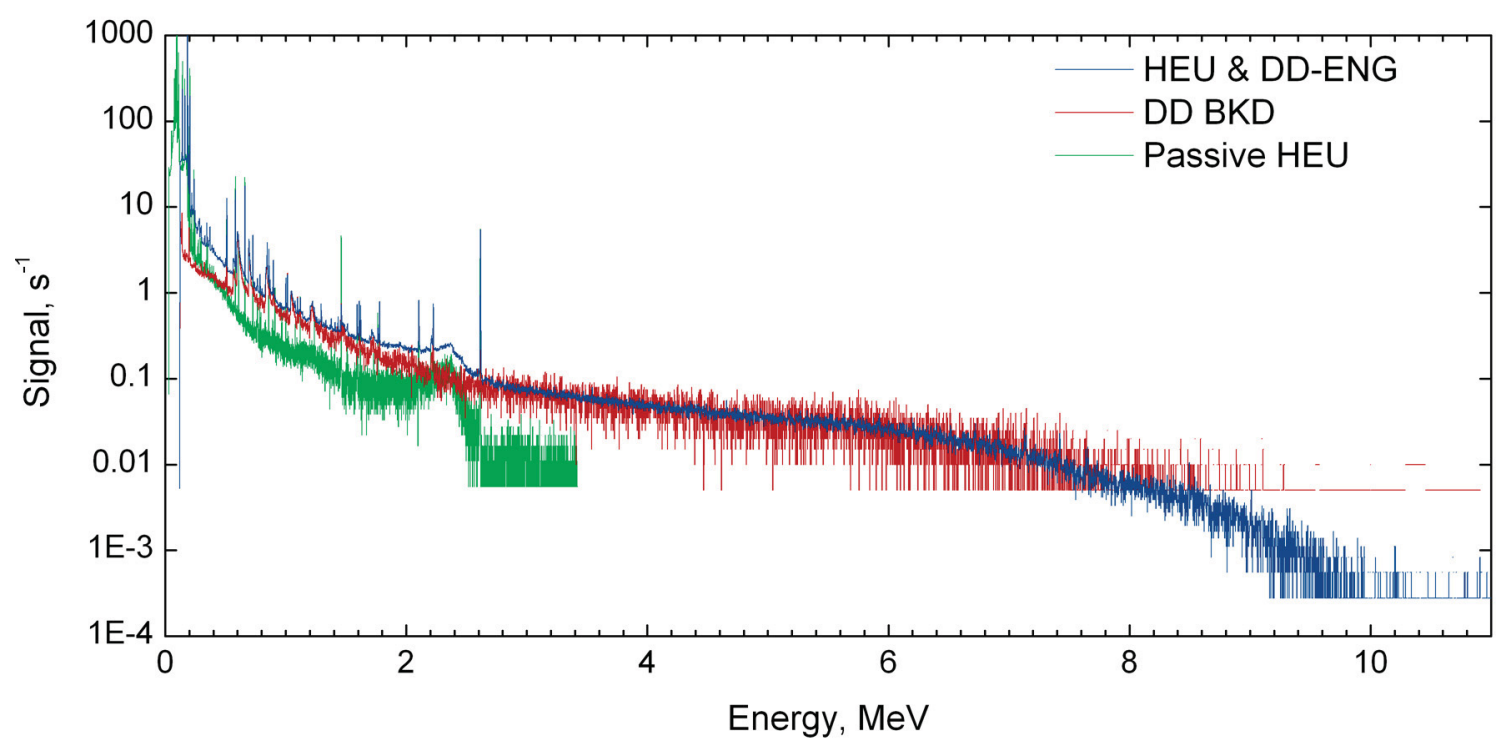

Figure 27 The passive gamma-ray spectra from a sample of highly enriched uranium (measured for 3600 livetime seconds, green), the PGNAA response of that sample using a DD-ENG neutron source (measured for 3600 livetime seconds, blue), and the PGNAA response of the empty test area (measured for 200 livetime seconds, red). 

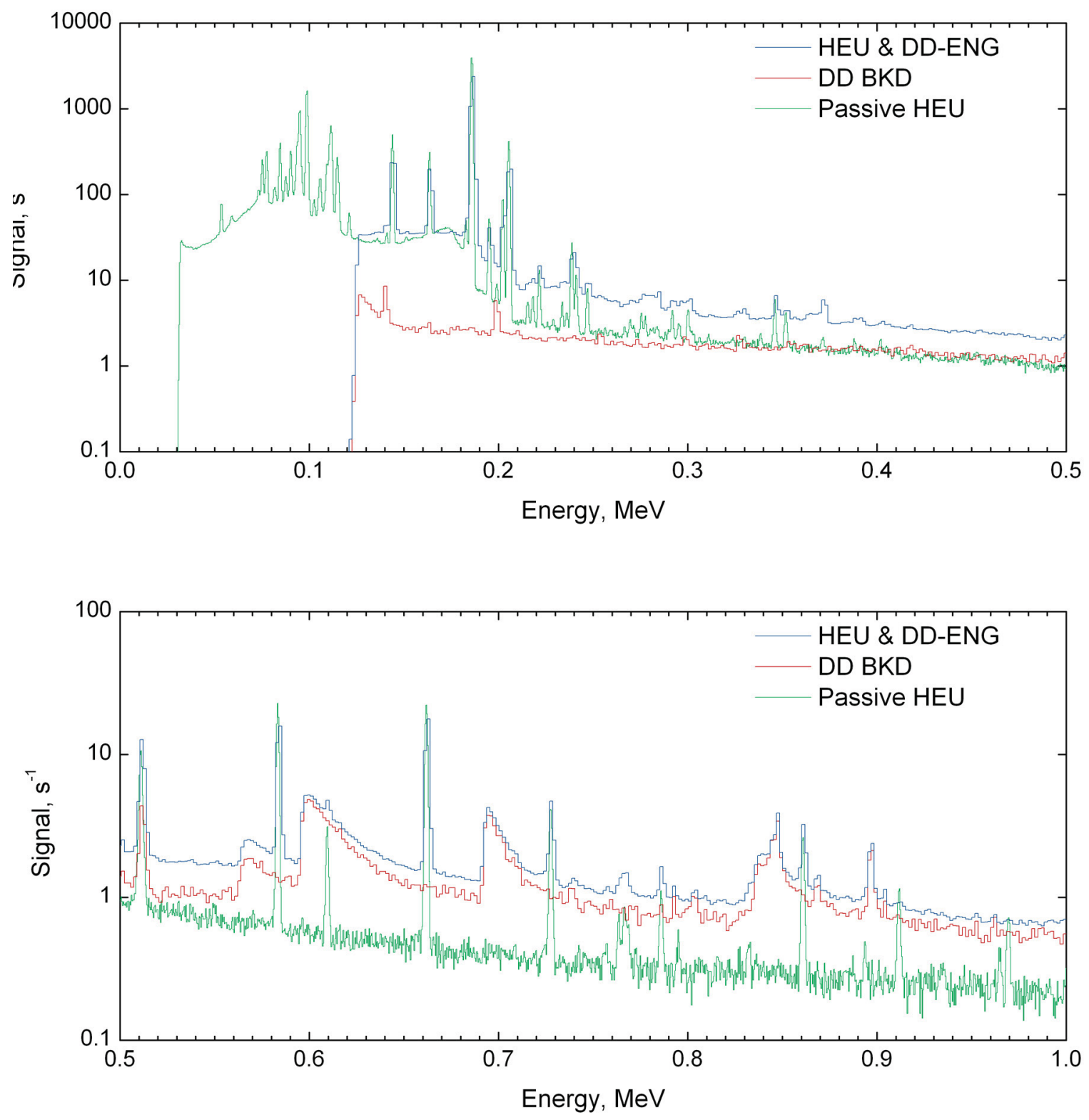

Figure 28 The passive, active, and active-background spectra for PGNAA measurements of HEU, as described in Figure 27; 0 - $0.5 \mathrm{MeV}$ and 0.5 - 1.0 MeV. 

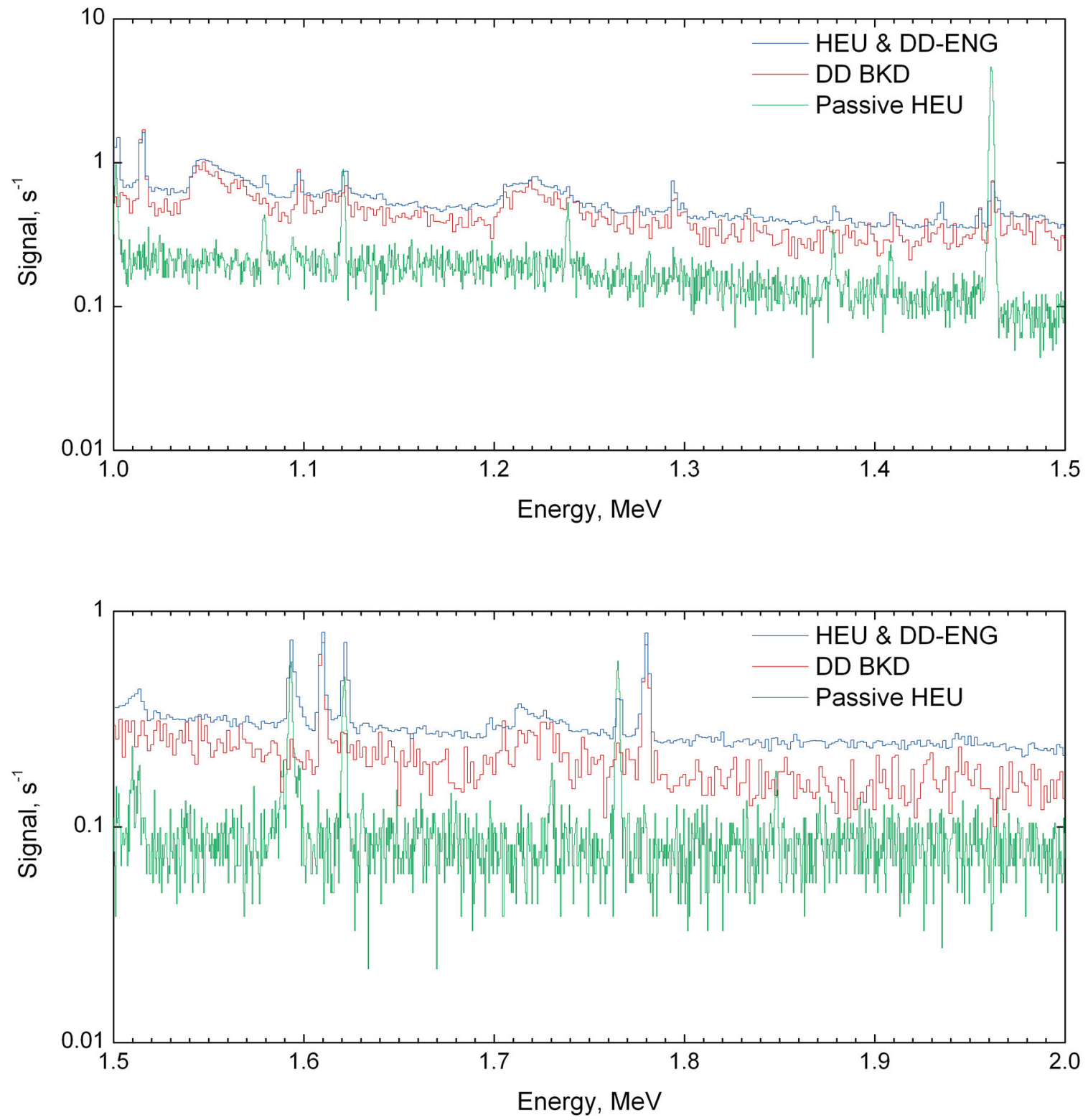

Figure 29 The passive, active, and active-background spectra for PGNAA measurements of HEU, as described in Figure 27; 1.0 - 1.5 MeV and 1.5 - 2.0 MeV. 

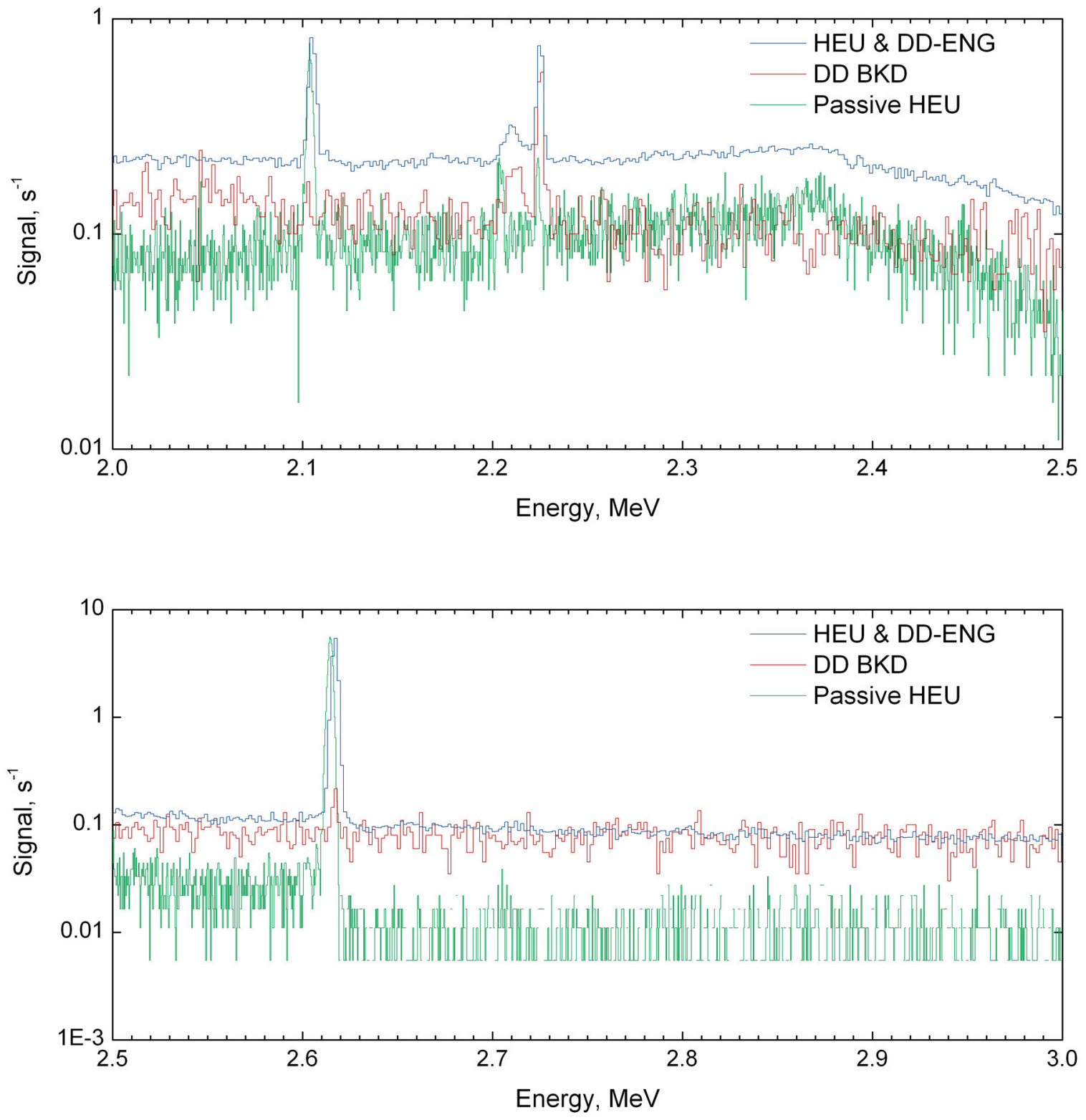

Figure 30 The passive, active, and active-background spectra for PGNAA measurements of HEU, as described in Figure 27; 2.0 - 2.5 MeV and 2.5-3.0 MeV. 

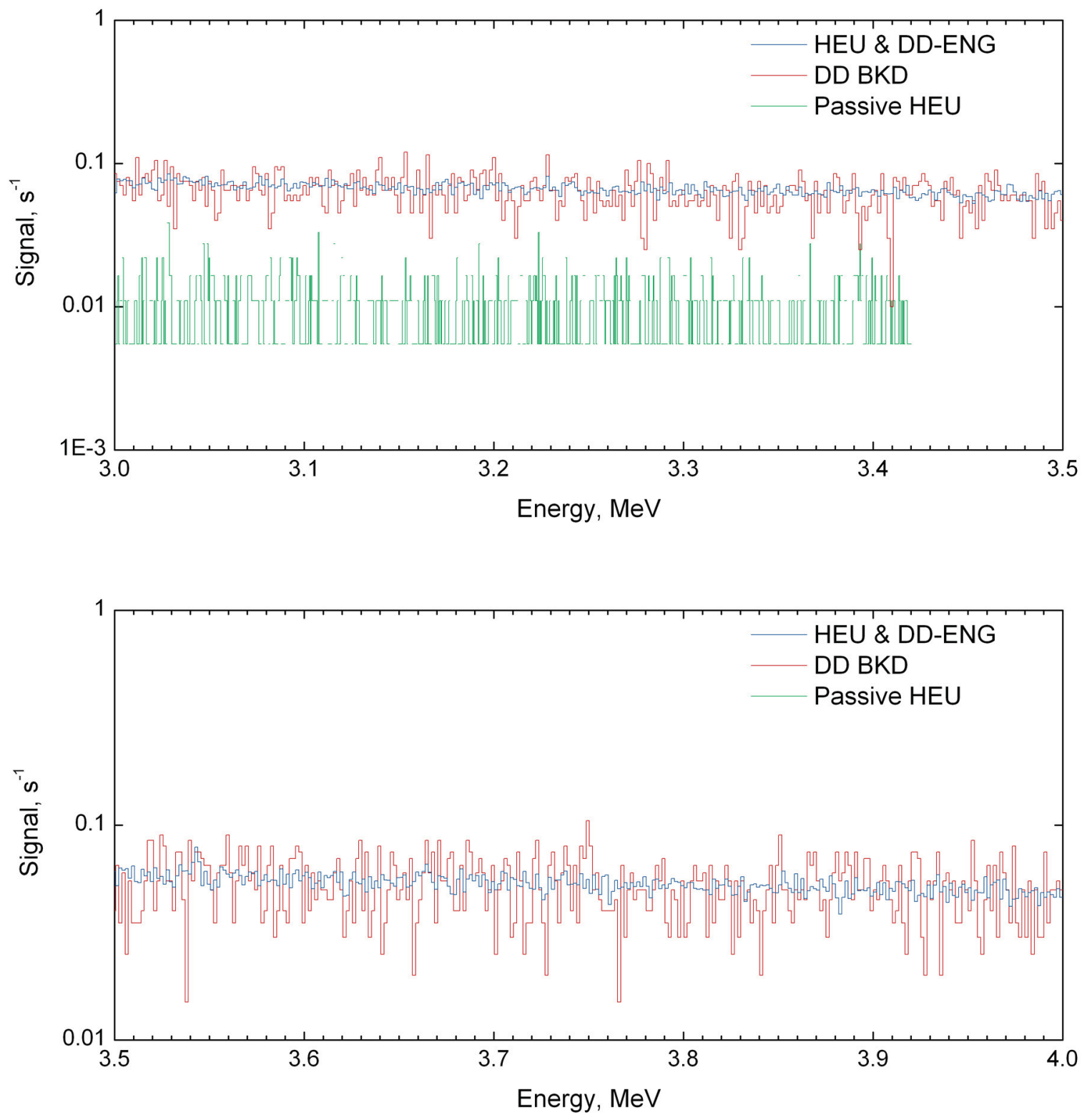

Figure 31 The passive, active, and active-background spectra for PGNAA measurements of HEU, as described in Figure 27; 3.0 - 3.5 MeV and 3.5 - 4.0 MeV. 

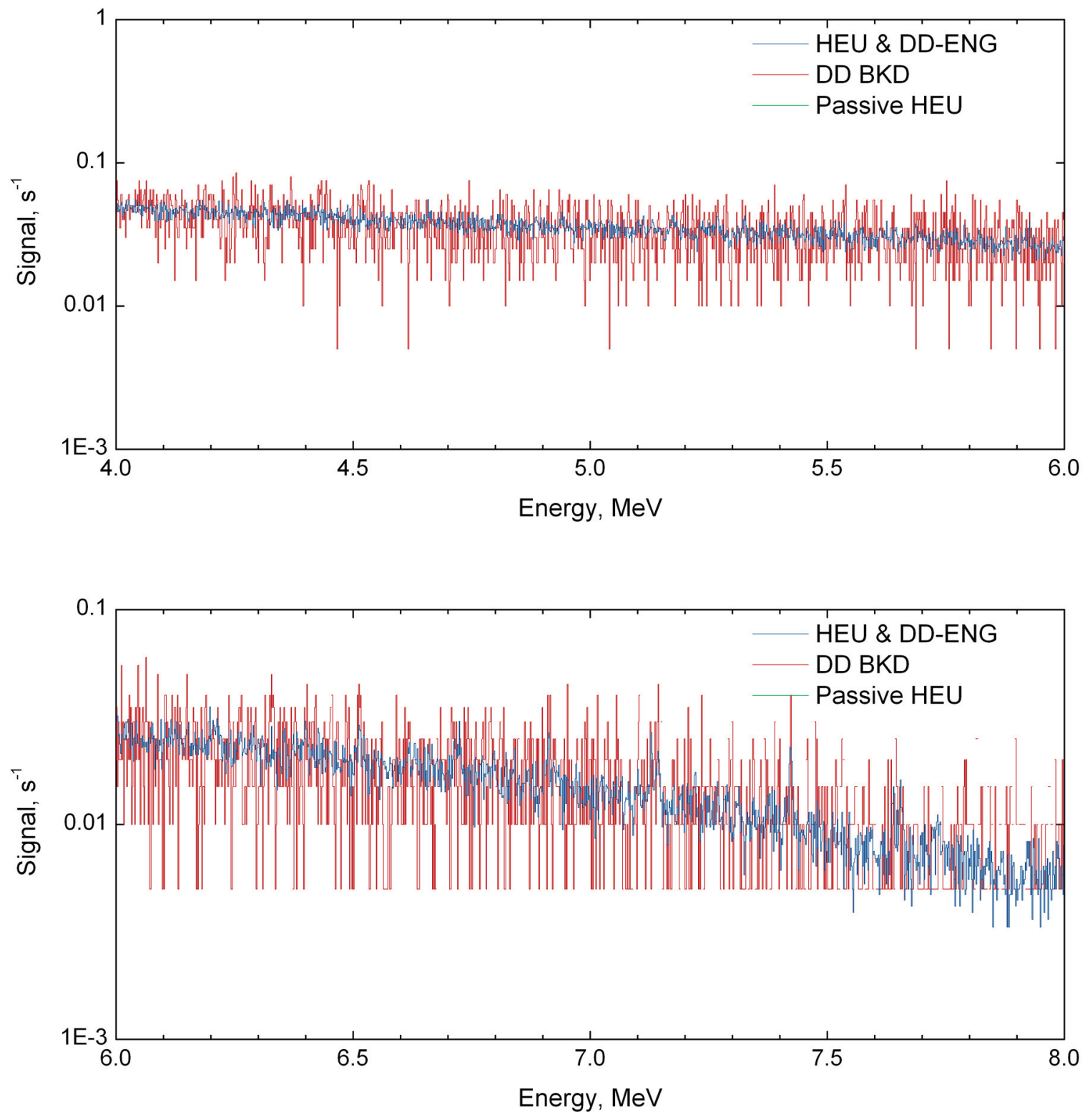

Figure 32 The passive, active, and active-background spectra for PGNAA measurements of HEU, as described in Figure 27; 4.0 - 6.0 MeV and 6.0-8.0 MeV. 


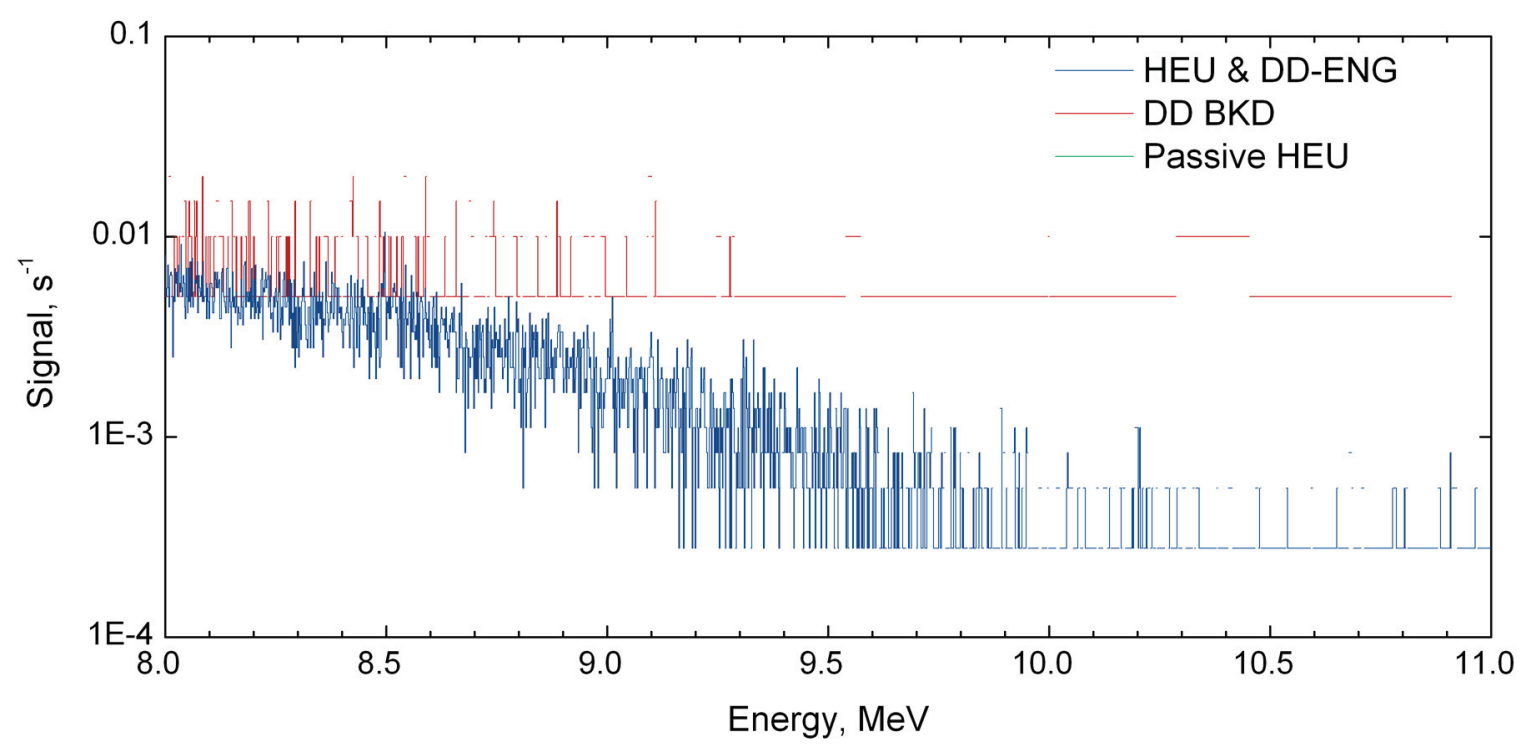

Figure 33 The passive, active, and active-background spectra for PGNAA measurements of HEU, as described in Figure 27; 8.0 - 11.0 MeV.

\section{Bulk NAA - Enriched Uranium Metal}

To complement the PGNAA data taken of the HEU $\left({ }^{235} \mathrm{U}\right)$ a traditional NAA data set was also taken of the yellowcake following the end of irradiation with the DD-ENG neutron source. This measurement sought to determine if any short-live fission product or activation products could be identified in the post-irradiation HEU. This data is shown in Figure 34 for the complete $0-11 \mathrm{MeV}$ gamma ray range. No distinguishable HEU NAA lines were identified. 


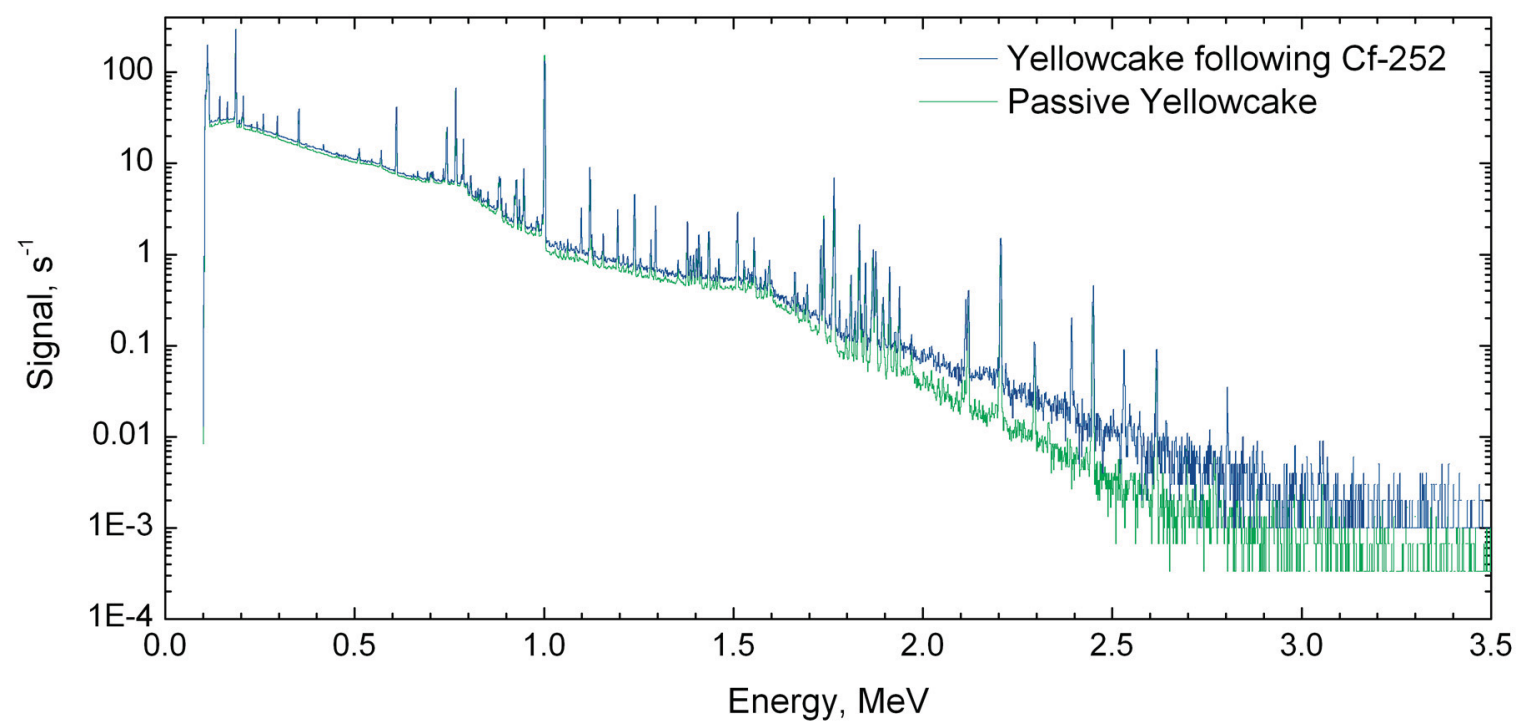

Figure 34 The passive gamma-ray spectra from a sample of highly enriched uranium metal (measured for 3600 livetime seconds, green) and the same sample following irradiation for 3600 seconds in an unmoderated configuration using a DD-ENG with a simple $10 \mathrm{~cm}$ polyethylene side reflector (measured for 1800 livetime seconds, blue).

\section{Ancillary Information - Detection of Oxygen Leading to Oxide Confirmation}

In our measurements at the PINS laboratory we also performed neutron interrogation experiments on the yellowcake using a DT-ENG. Overall the penetration ability of the high-energy neutrons exceeds that of the ${ }^{252} \mathrm{Cf}$ source, allowing more of these neutrons to completely exit the polyethylene moderating box without being reflected or theramalized in the vicinity of the yellowcake. Because of this PGNAA $(n, \gamma)$ signatures from the yellowcake (mostly its steel container) were significantly less with the DT-ENG then with the ${ }^{252} \mathrm{Cf}$. However, the (n,inl) signal achieved with the DT-ENG was notably higher than when using the ${ }^{252} \mathrm{Cf}$ source. These effects were most notable in the ability to detect oxygen in the yellowcake with the DT-ENG as the neutron source. This effect is illustrated in Figure 35, which shows the complete 0-11 MeV gamma spectra for the DT-ENG, ${ }^{252} \mathrm{Cf}$, and the DT-ENG active background from an empty box. Also shown in this figure is a zoom view from $5.5 \mathrm{MeV}$ to $6.5 \mathrm{MeV}$ allowing a clearer picture of the $6.129 \mathrm{MeV}$ gamma-ray that originates from ${ }^{16} \mathrm{O}(\mathrm{n} \text {,inl })^{16} \mathrm{O}$ and the decay of ${ }^{16} \mathrm{~N}$, which is produced via the ${ }^{16} \mathrm{O}(\mathrm{n}, \mathrm{p}){ }^{16} \mathrm{~N}$ reaction and which decays with a $7.13 \mathrm{~s}$ half life. The energetic DT neutrons are needed for this reaction because of the high energy threshold of the inelastic scattering and $(n, p)$ reactions. Prior work has demonstrated these measurements using NAA.[19,20] A small 6.129-MeV peak is observed from the empty box, a result of background air near the measurement apparatus, but a strong additional signal is seen with the yellowcake presence. These results have been tabulated and are presented in Table 5. Also clearly seen in the figure and the table is the fact that useful information may be gathered both from the main photopeak at $6.129 \mathrm{MeV}$ but also from the first escape peak of this gamma ray at $6.129-0.511=5.618 \mathrm{MeV}$. 

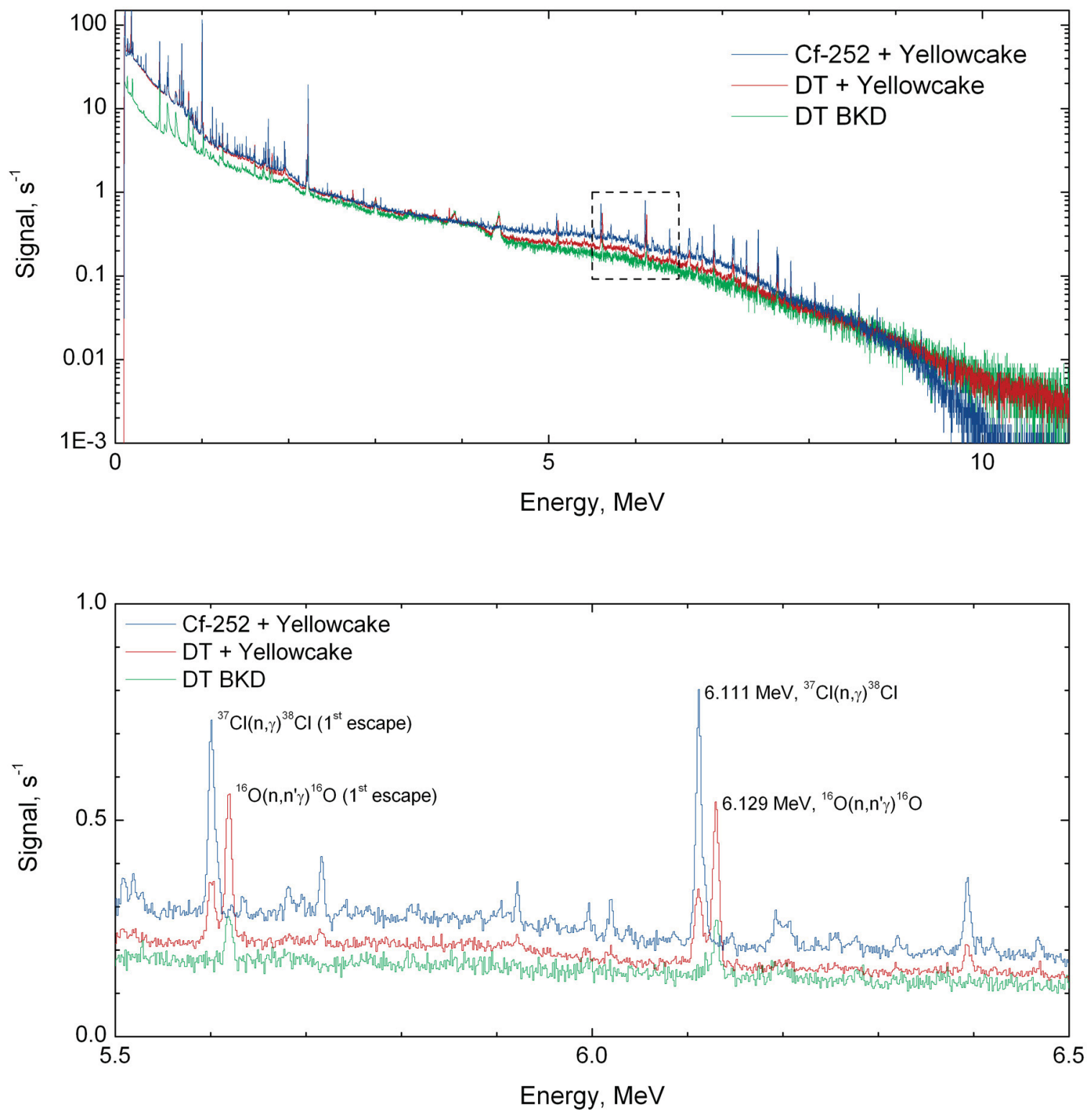

Figure 35 The upper panel shows the complete 0-11 MeV PGNAA gamma-ray spectra (log scale) taken a) with the yellowcake in the moderating box irradiated with a ${ }^{252} \mathrm{Cf}$ source (blue), b) with the yellowcake in the moderating box irradiated with a DT-ENG (red), and c) for an empty box irradiated with a DT-ENG (green). The lower panel shows an enlarged region of the upper plot, indicated by the dashed-line box above and with a linear scale, highlighting the fast-neutron inelastic scattering gamma-ray from oxygen.

These results suggest that the use of a DT-ENG for active neutron interrogation of uranium samples can be used to discriminate between uranium metal and uranium oxide samples. This capability may be of importance for current and future MPACT safeguards scenarios requiring measurements to confirm declarations of material form, in conjunction with material mass, in sealed storage containers. Prior work has demonstrated the use of passive measurement schemes to allow this discrimination in plutonium-bearing samples, taking advantage of self-interrogation effects using $(\alpha, n)$ reactions.[21] Related work has also demonstrated the use of PGNAA for measurements 
with plutonium, including moisture determination.[22,23] As a complimentary measurement approach neutron interrogation may be useful in these cases as well. For a deployed measurement system only a simple design would be needed to optimize the positing and shielding of the HPGe detector in relation to the DT-ENG, and to reduce the impact of room-return ${ }^{16} \mathrm{O}$ gamma rays. The polyethylene moderating box would not be needed.

Table 5 Comparison of the signal intensity for DT-ENG irradiation of an empty polyethylene moderating box and irradiation of the box filled with a nominal 7.7-kg sample of natural-enrichment yellowcake.

\begin{tabular}{|c|c|c|c|}
\hline Irradiation Case and Peak Signal & Net Counts & $\begin{array}{c}\text { Net Rate } \\
{\left[\mathbf{s}^{-1}\right]}\end{array}$ & $\begin{array}{c}\text { Background } \\
\text { Corrected Rate } \\
{\left[\mathbf{s}^{-1}\right]} \\
\end{array}$ \\
\hline \multicolumn{4}{|l|}{$D T-E N G$ Background $\left(\mathrm{T}_{\text {irradiation }}=1000 \mathrm{~s}\right)$} \\
\hline $6.129 \mathrm{MeV}$ & $469 \pm 93$ & $0.469 \pm 0.093$ & \\
\hline 5.618 MeV ( $1^{\text {st }}$ escape $)$ & $463 \pm 100$ & $0.463 \pm 0.100$ & \\
\hline \multicolumn{4}{|l|}{$D T-E N G+$ Yellowcake $\left(\mathrm{T}_{\text {irradiation }}=4000 \mathrm{~s}\right)$} \\
\hline $6.129 \mathrm{MeV}$ & $6891 \pm 221$ & $1.723 \pm 0.055$ & $1.254 \pm 0.108$ \\
\hline $5.618 \mathrm{MeV}\left(1^{\text {st }}\right.$ escape $)$ & $6344 \pm 246$ & $1.586 \pm 0.062$ & $1.123 \pm 0.118$ \\
\hline
\end{tabular}

\section{Summary}

During FY-2010 one small project has been conducted at INL as part of the MPACT neutron interrogation program; namely, a study of the utility of using neutron interrogation and small-scale, portable PGNAA systems for safeguards measurements with uranium. Success has been described in the literature for using PGNNA in this area when using reactor-based neutron sources and high-yield electronic neutron generators. Unfortunately, the small reaction cross sections for the interactions of interest in this area lead to the conclusion that the lower-yield neutrons sources available in field-portable PGNAA instruments, such as INL's PINS system, are insufficient for routine safeguards measurements in most cases. Neutron interrogation and PGNAA may be of use when using higher yield neutron sources or with the use of a more elaborate fixed-installation approach, such as in the generation of fission products for assaying fission product yield ratios and determining uranium enrichment.

Using a DT-ENG irradiation source neutron interrogation has been shown as a potentially useful method for confirming declaratory statements regarding the physical form of fissile material - oxide versus metal. Similar success would also be expected for the identification of other physical forms including nitrides, fluorides, carbides, and sodium-bonded metals. These capabilities may be of particular relevance within the long term programmatic goals of the Fuel Cycle Research and Development program depending upon choices to be made for next-generation fuel cycle fuel forms.

\section{Acknowledgement}

The authors would like to acknowledge Daren Norman, Kevin Haskell, Collin Knight, and the INL health physics staff for their assistance in coordinating and 
supporting the experiments described in this report. The work in this report was sponsored by the U.S. Department of Energy's Fuel Cycle Research and Development program and its Materials Protection, Accounting, and Control for Transmutation (MPACT) campaign. Additional support was also provided by INL in the form of Laboratory Directed Research and Development funds from INL's Nuclear Nonproliferation Initiative.

\section{References}

1 Chichester, D. L., et al., "FY09 Advanced Instrumentation and Active Interrogation Research for Safeguards," Report INL/EXT-09-16611, Idaho National Laboratory, Idaho Falls, Id. (2009).

2 Caffrey, A. J., Cole, J. D., Gehrke, R. J., and Greenwood, R. C., "Chemical Warfare Agent and High Explosive Identification by Spectroscopy of Neutron-Induced Gamma Rays," IEEE Trans. Nucl. Sci. 39 (1992) 1422-1426.

3 Keepin, G. R., Physics of Nuclear Kinetics, Addison-Wesley Publishing Company, Reading, Mass. (1965).

4 Maslov, V. M., "Prompt-Fission-Neutrons Spectra of ${ }^{238}$ U," Phys. Atomic Nuclei 71 (2008) 9-26.

5 Valentine, T. E., "Evaluation of Prompt Fission Gamma Rays for Use in Simulating Nuclear Safeguards Measurements," Annals Nucl. Energy 28 (2001) 191-201.

6 Chichester, D. L. and Seabury, E. H., "Active Neutron Interrogation to Detect Shielded Fissionable Material," Proc. International Topical Meeting on Nuclear Research Applications and Utilization of Accelerators, International Atomic Energy Agency, Vienna, Austria, May 4 - 8 (2009) SM/EN-02.

7 Weitkamp, C., Matussek, P., and Ottmar, H., "Nondestructive Nuclear Fuel Assay by Neutron Capture Gamma-Ray Spectrometry," Proc. Int. Symp. Neutron Capture Gamma Ray Spectrometry and Related Topics, 2nd, K. Abrahams, K., StecherRasmussen, F., and Van Assche, P., eds., Reactor Centrum Nederland, Pettten, The Netherlands (1975) 749-753.

8 Beddingfield, D. H., "Identification and Quantification of $\mathrm{Pu}$ and $\mathrm{U}$ from Fission Product Gamma-Ray Spectra," Ph.D. Thesis, Colorado School of Mines, Golden, Colo. (1996).

9 Chrien, R. E., et al., "High-Energy $\gamma$-Rays Following Neutron Capture in ${ }^{239} \mathrm{Pu}$ and ${ }^{235} \mathrm{U}$, Report IAEA-CN-26/42, International Atomic Energy Agency, Vienna, Austria (1970).

10 "Atlas of Gamma-Ray Spectra from the Inelastic Scattering of Reactor Fast Neutrons," Report INDC(CCP)-120, International Nuclear Data Committee, International Atomic Energy Agency, Vienna, Austria (1978).

11 Blinov, M. V., et al., "The Spectra of Gamma-Rays from the Interaction of 3-MeV Neutrons with ${ }^{232} \mathrm{Th},{ }^{235} \mathrm{U}$, and ${ }^{238} \mathrm{U}$ Nuclei," in "Translation of Selected Papers Published in Nuclear Constants, No. 3 (57), Moscow 1984," Report INDC(CCP)281/L, International Nuclear Data Committee, International Atomic Energy Agency, Vienna, Austria (1978) 5-16.

12 Chrien, R. E., et al., "Distribution of Radiative Strength from Neutron Capture by ${ }^{239} \mathrm{Pu}, "$ Nucl. Phys. A 436 (1985) 205-220. 
13 Bushuev, A. V., Zubarev, V. N., and Proshin, I. M., "Possibility of Activation $\gamma$ Spectrometric Measurements for Determining the Masses of Nuclear Materials in Samples," Atomic Energy 93 (2002) 823-826.

14 Molnár, G. L., et al., "Non-Destructive Interrogation of Uranium Using PGAA," Nucl. Inst. Meth. Phys. Res. B 213 (2004) 389-393.

15 Firestone, R. B., et al., "Analysis of Fissile Materials by High-Energy NeutronInduced Fission Decay Gamma-Rays," J. Radioanal. Nucl. Chem. 265 (2005) 241245.

16 Newton Nathaniel, T., et al., "Non-Destructive Assay Technique for the Determination of ${ }^{238} \mathrm{U} /{ }^{232} \mathrm{Th}$ Ratio in the Mixed Oxides of Uranium and Thorium Using Prompt Gamma-Ray Neutron Activation," J. Radioanal. Nucl. Chem. 279 (2009) 481-485.

17 Molnár, G, ed., Handbook of Prompt Gamma Activation Analysis with Neutron Beams, Kluwer Academic Publishers, Dordrecht, The Netherlands (2004).

18 Yamashita, N., et al., "Gamma Rays from Major Elements by Thermal Neutron Capture Reactions: Experiment and Simulation for Planetary Gamma-Ray Spectroscopy," Abstract 88, Proc. Vernadsky/Brown Microsymposium on Comparative Planetology, October 12-14, Moscow, Russia (2004).

19 C. E. Calado, E. L. Machado, L. Holland, "Measurement of Oxygen Content of Uranium Oxide Fuel and Steel," Technical Report IEA-425, Institute of Atomic Energy, Sao Paulo, Brazil (1976).

20 Anderson, M., "Assay for Oxygen in Uranium in the $0.1-1.0$ WT\% Range Using 14MeV Neutron Activation," J. Radioanal. Nucl. Chem. 100 (1986) 373-380.

21 Mercer, D. J., et al., "Discrimination Between $\mathrm{PuO}_{2}$ and $\mathrm{Pu}$ Metal by Gamma-Ray Spectroscopy for Arms Control Transparency," Report LA-UR-01-4870, Los Alamos National Laboratory, Los Alamos, N.M. (2001).

22 Prettyman, T. H., Foster, L. A, and Staples, P., "Application of PGNAA to Plutonium Surveillance," Trans. AM. Nucl. Soc. 77 (1997) 146-147.

23 Holslin, D., Verbinski, V., and Foster, L., "Moisture Probe Using Neutron Moderation for $\mathrm{PuO}_{2}$ Canister Inspection," Trans. AM. Nucl. Soc. 77 (1997) 147-148. 


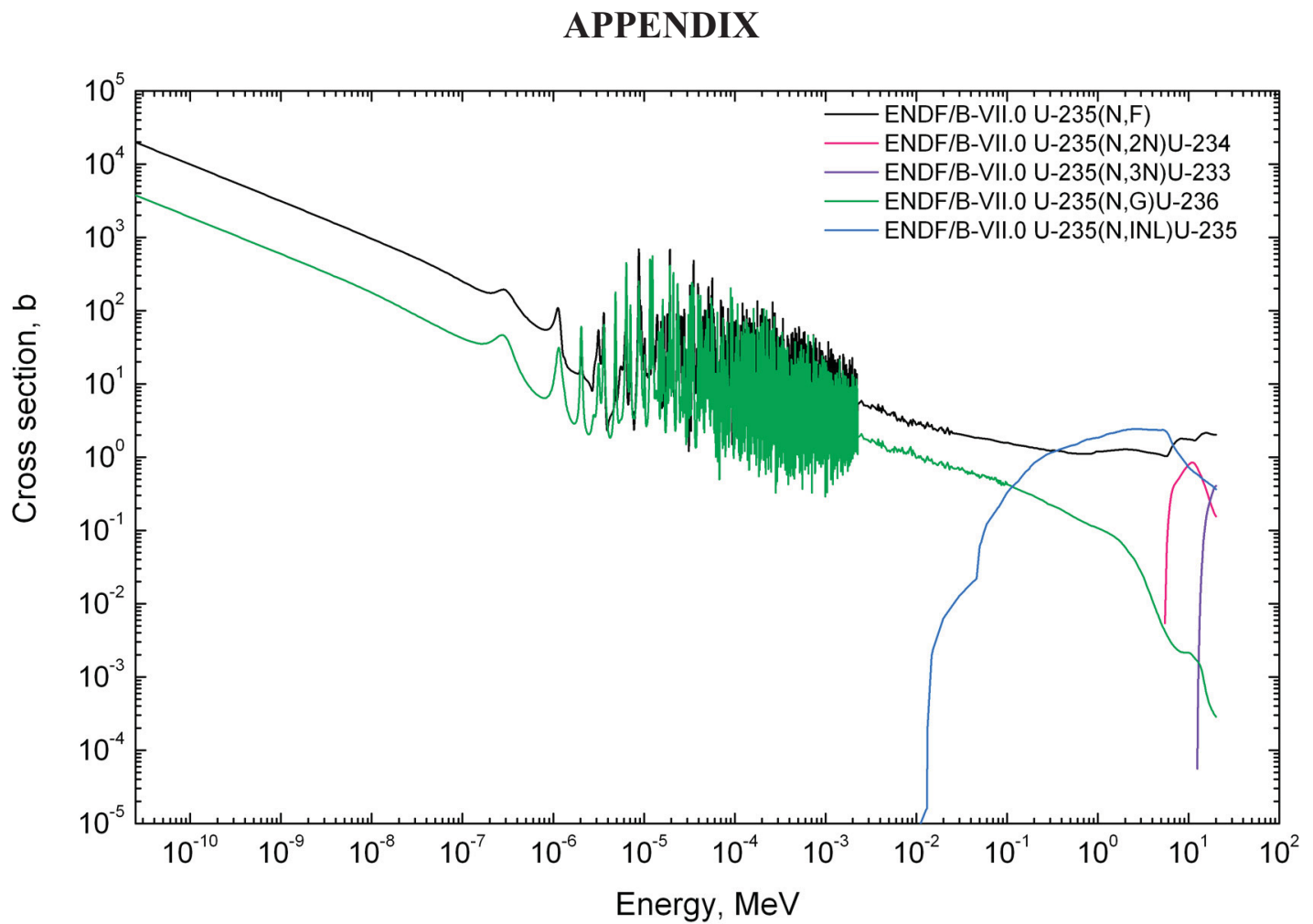

Figure 36 Important neutron interrogation reaction cross sections for ${ }^{235} \mathrm{U}$.

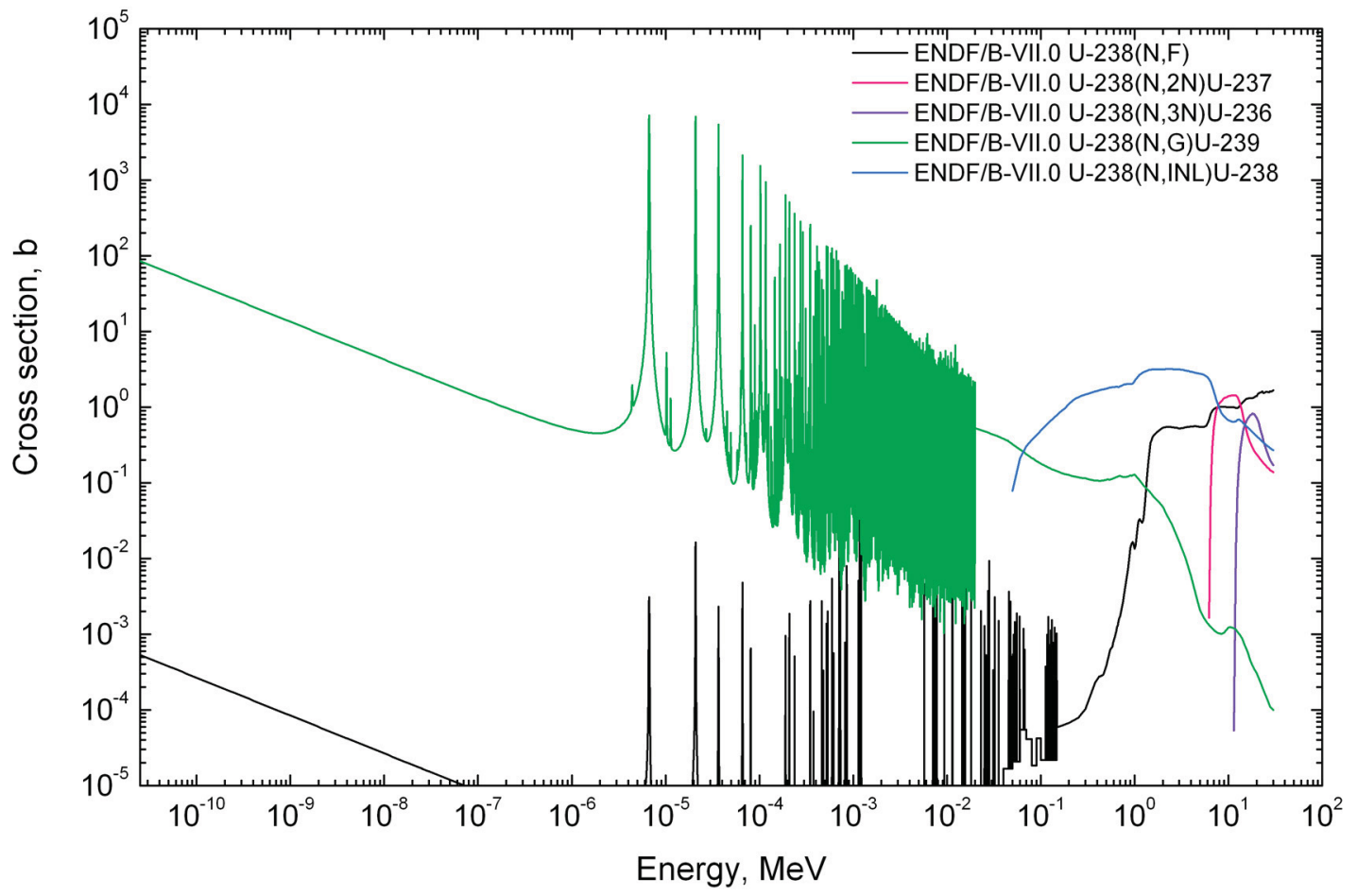

Figure 37 Important neutron interrogation reaction cross sections for ${ }^{238} \mathrm{U}$. 


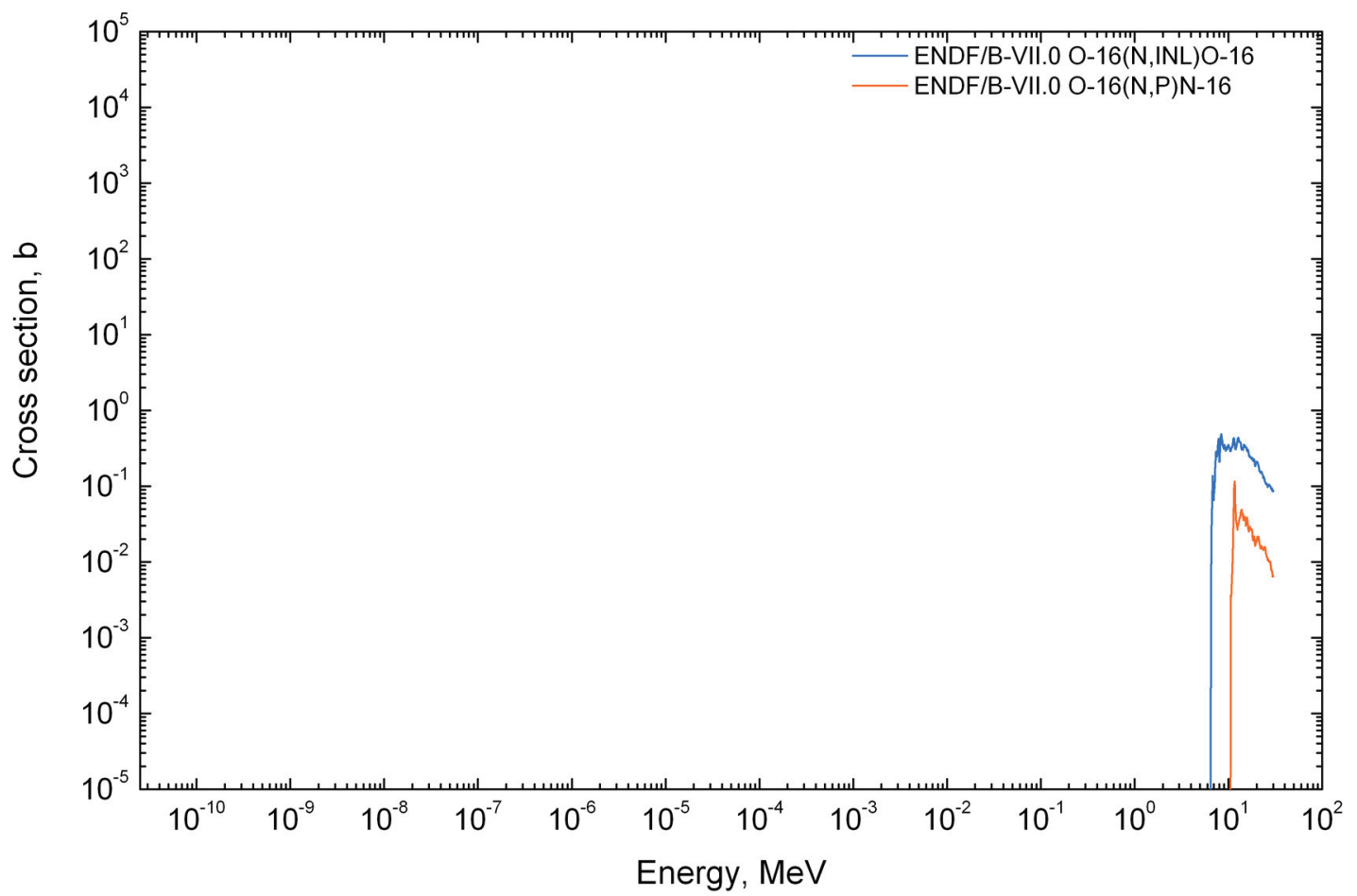

Figure 38 Important neutron interrogation reaction cross sections for ${ }^{16} \mathrm{O}$.

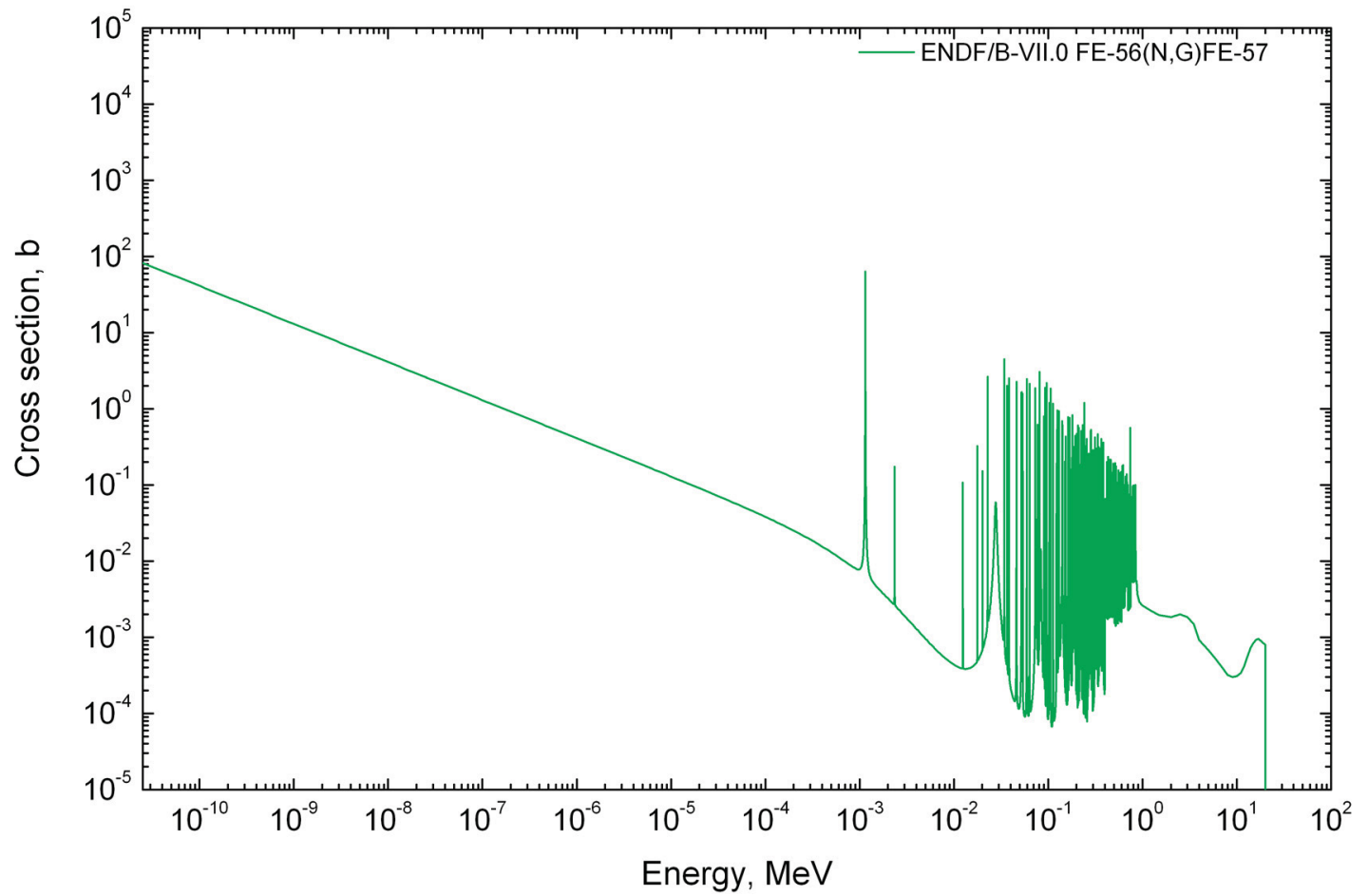

Figure 39 Important neutron interrogation reaction cross sections for ${ }^{56} \mathrm{Fe}$. 